\title{
The Exploitation of Polymer Based Nanocomposites for Additive Manufacturing: A Prospective Review
}

\author{
Imran Khan ${ }^{1, a^{*}}$, Christina S. Kamma-Lorger ${ }^{2, b}$, Saeed D. Mohan ${ }^{3, c}$, \\ Artur Mateus ${ }^{1, d}$ and Geoffrey R. Mitchell ${ }^{1, e}$
}

\author{
${ }^{1}$ Center for Additive and Sustainable Product Development, Centro Empresarial da Marinha \\ Grande, Rua de Portugal - Zona Industrial, 2430-028 - Marinha Grande, Portugal \\ ${ }^{2}$ NCD beamline, Alba Synchrotron Light Source, Cerdanyola del Vallès 08290, Spain \\ ${ }^{3}$ Department of Chemistry, University of Reading, Whiteknights, Reading, RG6 6AD, UK \\ aimran.khan@ipleiria.pt ,bckammalorger@cells.es, cs.d.mohan@reading.ac.uk, \\ dartur.mateus@ipleiria.pt, egeoffrey.mitchell@ipleiria.pt \\ *imran.khan@ipleiria.pt
}

Keywords: Additive Manufacturing, Nanoparticles, Nanocomposites

\begin{abstract}
Additive manufacturing (AM) is a well-known technology for making real three dimensional objects, based on metal, ceramic and plastic material used for various applications. The aim of this review is to explore and offer an insight in to the state of the art polymer based nanocomposites in to additive manufacturing applications. In context to this, the developing efforts and trends in nanocomposites development particularly for additive manufacturing processes were studied and summed up. The scope and limitations of nanocomposites into Stereolithography, selective laser sintering and fused deposition modeling was explored and highlighted. The review highlights widely accepted nanoparticles for range of applications including mechanical, electrical, flame retardance and crossing over into more biological with the use of polymer matrices. Acquisition of functional parts with limitations in regard to printing is highlighted. Overall, the review highlights successes, limitations and opportunities that the union of AM and polymer based nanocomposites can bring to science and technology.
\end{abstract}

\section{Glossary of terms and abbreviations:}

Carbon nanotubes - CNT

Single-walled carbon nanotubes - SWCNTs

Graphene- $\mathrm{Gr}$

Carbon black $(<0.03 \mu \mathrm{m})-C B$

Transmission electron microscope - TEM

Electrical conductivity - EC

Selective laser sintering - SLS

Additive manufacturing-AM

Additive prototyping $-R P$

Three-dimensional printing - $3 D P$

Polystyrene - PS

Poly (vinyl alcohol) - PVA

Polyurethane foams - PUF

Polyamide-11-PA11

Polybutylene terephthalate $-P B T$

Poly(D,L-lactide) - PDLLA

Poly (e-caprolactone) diacrylate-PCLDA

Poly(trimethylene carbonate) - PTMC

Polydimethylsiloxane-PDMS

Natural graphite - NG ( $\mu m 75-150)$
Multi-walled carbon nanotubes - MWCNTs

Double-walled carbon nanotubes - DWCNTs

Carbon fiber ( $\mu \mathrm{m} 150)-C F$

Carbon fibre reinforced polymer - CFRP

Scanning electron microscope - SEM

Aerosol jet printing - (AJP)

Fused deposition modelling - FDM

Computer aided design-CAD

Sterolithography - SL

Nanoparticles - NP

Poly (methyl methacrylate) - PMMA

Polyurethane - PU

Polyamide-6 - PA6

Polyamide-12 - PA12

Twin screw extrusion - (TSE)

PA Polyamide or Nylon - PA

Hydroxyapatite - HA

nanocrystalline silicon - (nc-Si)

Yttrium stabilised zirconia - YSZ

Synthetic graphite ( $\mu$ m10-45) - SG 
Calcium phosphate - CaP

Poly (D,L-lactide:glycolide) - DL-PLGA

Drug delivery system - DDS

Poly(hydroxybutyrate-co-hydroxyvalerate - $P H B V$

2-hydroxyethyl acrylate/polyethyleneglycol 200 diacrylate - HEA/M282

Organically modified dimethyl benzohydrogenated montmorillonite - omMMT

\section{Introduction}

Composite materials have been widely studied with examinations focused upon how the host material is influenced by the presence of one or more additional components (fillers). Nanocomposites are defined as a class of materials that contain at least one phase with constituents in the nanometer domain [1]. The literature suggests that the use of nanoparticles influence the various features of a host material making it suitable for applications ranging from drug delivery [2], corrosion prevention [3], electrical [4], electronic [5], aeronautics and automotive[6] parts to industrial equipment [7]. The development of nanocomposite materials is currently an area of great research interest due to the benefits of producing materials with enhanced features [8].

Table 1. Differentiation of AM according to nature of matrix material

\begin{tabular}{ccc}
\hline Type & AM Technologies & Host Materials \\
\hline Extrusion & Fused deposition modelling (FDM) & $\begin{array}{c}\text { Thermoplastics (e.g. PLA, } \\
\text { ABS), eutectic metals }\end{array}$ \\
\hline & $\begin{array}{c}\text { Direct metal laser sintering (DMLS) } \\
\text { Electron beam melting (EBM) } \\
\text { Selective heat sintering (SHS) }\end{array}$ & \\
Granular & Selective laser sintering (SLS) & Metal /Alloy/Polymer \\
& Powder \\
& Powder bed and inkjet head 3d & printing, Plaster-based 3D printing \\
& (PP) & Photopolymer \\
\hline \multirow{2}{*}{ Light polymerised } & Stereolithography (SL) & \\
\hline
\end{tabular}

Although the advent of nanotechnology can have a huge potential impact on product development, the lack of consistent manufacturing techniques limit its wide use in different industries. A consistent and cost effective route is the need of the hour to fully benefit from nanocomposite materials. Moreover, consistency is quite a relative factor when producing parts on a bulk scale; say 100 or 1000 parts for instance. Moreover, all the manufactured parts require the same features. A consistent way to achieve such a desired nano precision and resolution is the development and wide implementation of nanofabrication technologies [9]. The fast and quick delivery of nanocomposites with enhanced features can be achieved with the application of AM. AM refers to a group of technologies that build physical objects directly from 3D Computer-Aided Design (CAD) data. It is defined as the process of joining materials to make objects from 3D model data, usually layer upon layer, as opposed to subtractive manufacturing methodologies. A complex shaped model or piece to suit a specific function can be easily manufactured using AM through CAD. Ideally, the manufactured part should have properties suited for its application, such as good mechanical, electrical or parts compatible with biological features. AM can be used in variety of fields ranging from forming direct parts for aerospace, household appliances, automotive and biomedical applications [10] as it gives the designers an ability to design and turn concepts into 3D models or 3D prototypes. Amongst all, mechanical [11], thermal [12], electrical [13] and flame 
retardance [14] are the core characteristics which have attracted the interest for incorporation of nanomaterials into the AM process. Table 1 distinguishes AM techniques on the basis of feedstock or input material that after processing transform into a $3 \mathrm{~d}$ object of desired geometry.

The review examines the work conducted on the use of nanocomposites in AM or more precisely developing trends in manufacturing with the use of nanoparticles. After the brief introduction about nanoparticles, nanocomposites and additive manufacturing, the incorporation of nanocomposites into AM like stereolithography (SL), selective laser sintering (SLS) and fused deposition modelling (FDM) is presented. Stereolithography, selective laser sintering and fused deposition modelling are considered potential additive manufacturing techniques to review the published literature keeping in mind the processing polymer belongs to either liquid, powder or filament type. For the sake of discussion, all the light dependent curing, sintering and extrusion methods are discussed under the topics of SL, SLS and FDM techniques, respectively. The review end with the discussion about critical factors and suggestions to incorporate nanocomposites into AM to get functional 3D printed parts.

Potential Nano Particles. All kinds of solid particles with at least one characteristic dimension in the $100 \mathrm{~nm}$ range are referred as nanoparticles. In general all size effects may have both a classic and quantum nature. As the size of particles is reduced from macro to nano-scale a dramatic change in all its properties is observed as quantum size effects becoming more and more relevant. This leads to occur unusual physical properties of nanoparticles (NPs) below $100 \mathrm{~nm}$, significantly different from their bulk particles (micro or bigger sizes), where the size of the particle appears to dictate its physical and chemical properties. For example, a nanoparticle of silver will respond to photons and electrons in ways profoundly different from a larger particle or bulk silver [15]. This may be attributed to the particle's surface to volume ratio at this scale, which is considerably high and is beneficial for interacting with the surrounding environment, i.e. the host material. The presence of neighbouring surfaces, containing 0-D, 1-D, and 2-D nanostructures, causes a change in the distribution of the phonon group velocities as a function of phonon wavelength which affects overall thermal conductivity. From this it is evident that size does matter and is elaborated in a comparative chart (Fig.1) to highlight the importance of size scale. There are numerous forms of NP that can be used, from metallic to carbonaceous, clay, ceramic and semiconducting nanoparticles. Examples of use of these various NP are discussed throughout this article.

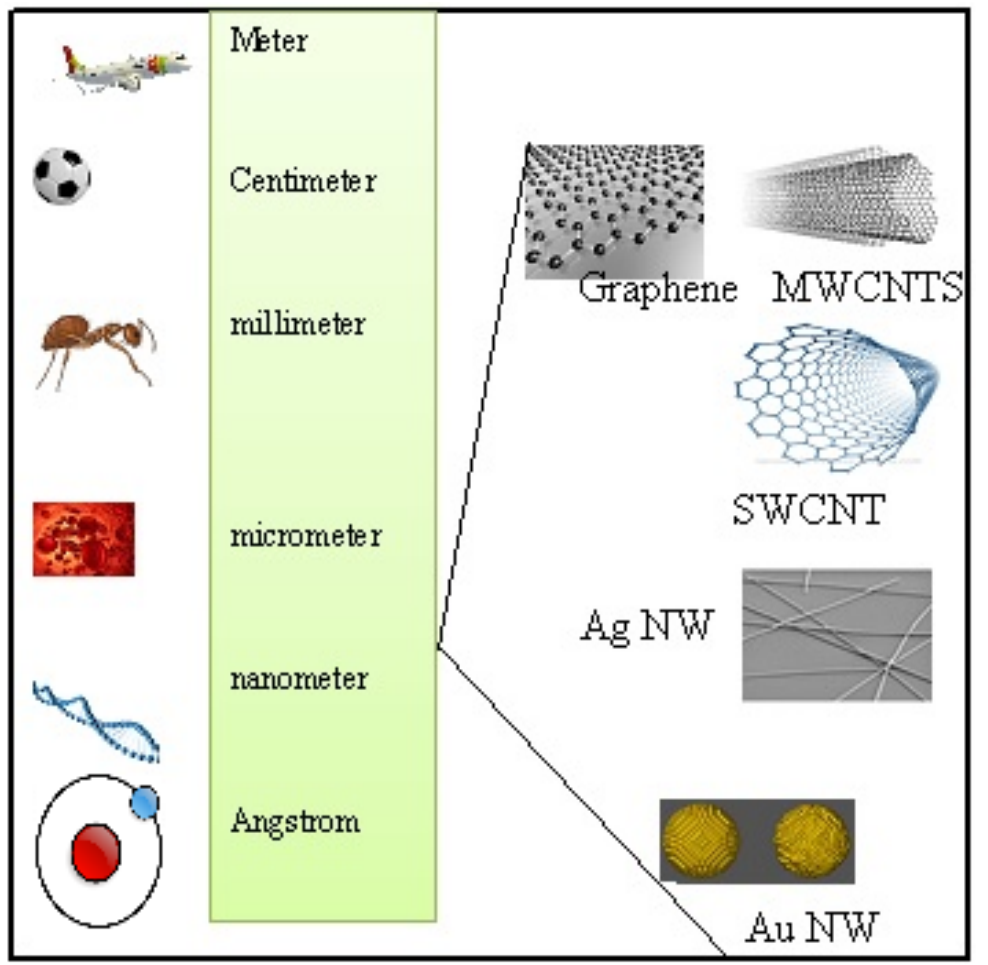

Figure 1. A comparative chart to compare sizes nano to macro scale objects. 
Overall the choice of filler particle used will depend on the desired properties for the composite material that is to be manufactured. For example, the carbonaceous nanoparticle, carbon nanotubes are widely studied as an option for incorporation into a host material as they have ability to improve electrical and thermal properties of the host material without sacrificing mechanical features. Different types of commercially available NP are mentioned in Table 2.

Table 2. Some of the commercially available nanoparticles.

\begin{tabular}{lll}
\hline Acronyms & Nanoparticles & Features \\
\hline SWCNT & Single wall carbon nanotubes & Electrical \& Mechanical \\
MWCNT & Multiwall wall carbon nanotubes & Electrical \& Mechanical \\
DWNT & Double wall carbon nanotubes & Electrical \& Mechanical \\
G or GO & Graphene or graphene oxide & Electrical \& Mechanical \\
AgNP & Silver nano particles & Electrical \& Antimicrobial \\
$\mathrm{AuNP}$ & Gold nanoparticles & Electrical \& Antimicrobial \\
$\left(\mathrm{Fe}_{3} \mathrm{O}_{4}\right) \mathrm{NP}$ & Iron oxide & Electrical \& Magnetic \\
$\mathrm{SiNP}$ & Silica NP & Mechanical \\
$\mathrm{Pd} \mathrm{NP}$ & Palladium nanoparticles & Electrical \& Catalytic \\
$\mathrm{Rh} \mathrm{NP}$ & Rhodium nanoparticles & Chemical \& Catalytic \\
$\mathrm{NaM} \mathrm{NP}$ & Sodium Metatitanate & Chemical \& Catalytic \\
$\mathrm{BNP}$ & Boron nitride & Electrical \& Thermal \\
$\mathrm{TiO} N \mathrm{NP}$ & Titanium dioxide & Antiseptic \& antibacterial \\
$\mathrm{CuONP}$ & Copper(II) oxide & Electrical \& Catalytic \\
$\mathrm{PbS}(\mathrm{CdSe})$ & PbS (CdSe) quantum dots & biomedical \& Photonic \\
$\mathrm{Cts} \mathrm{NP}$ & Chitosan NP & Pharmaceutical \\
\hline
\end{tabular}

Additive Manufacturing (AM). In the AM process the discrete slices are obtained from 3D CAD geometry. These slices are directly related to the build layers of the AM process targeted for manufacture. The continual recreation of the discrete adjacent slices, layer by layer, via the AM system, allows one to manufacture a virtual and complex geometry of a part [16]. The process involved in the AM is indicated in Fig. 2. AM is characterized by assembling layers using only the materials required, as opposed to subtractive manufacturing which involves cutting and wasting of material not needed from larger pieces of the material. The input material is sometimes referred as feedstock material which can be in the form of powder, pellets, liquid or filament. The selection of AM process also depends on the type of feedstock material. For instance, fused deposition modelling (FDM) is utilizing filament kind of feedstock material to print part in a layer by layer fashion. The competitive advantages of AM include an enormous range of shape complexity, rapid delivery of parts and deskilling of some of the manufacturing steps. These advantages had led to considerable enthusiasm for AM. Along with these encouraging signs, AM has come speculation about future benefits that are less certain. Many of AM technologies still have well known challenges. These include slow build rate, poor surface finishing, dimensional tolerances, expensive equipment, high material costs and limited material choices [17]. 


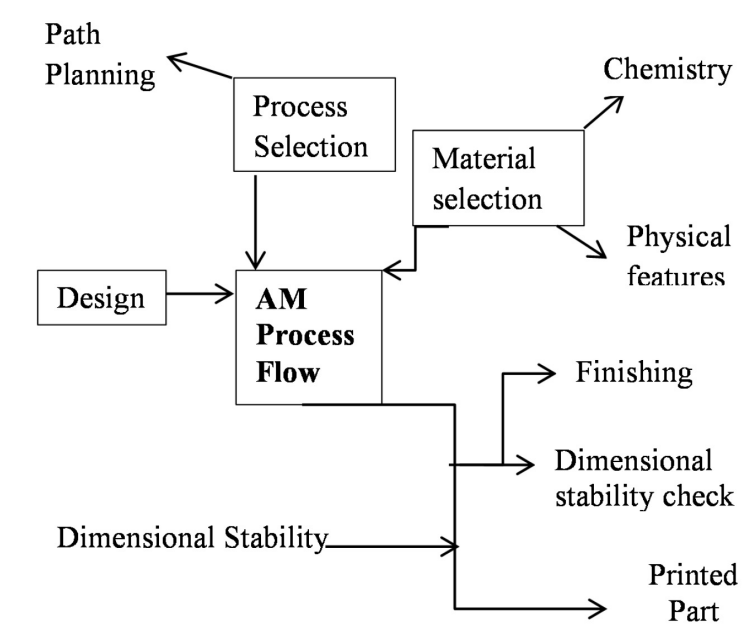

Figure 2. Schematic of additive manufacturing process flow.

Accuracy of the printed parts depends on functionality caused by nano additives, part design and dimensional stability compare to other fabrication methods. As an example, a comparative study related to dimensional error for the PolyJet, SLS and 3DP techniques was studied for medical models by Mika Salmi [18]. The accuracy in case of PolyJet was reported higher when compared with SLS or 3DP techniques while the repeatability of the measurements was excellent in case of 3DP as compare to rest of the techniques [18]. These results can help clinicians/ manufacturer to choose a suitable AM technique that yield results with an excellent accuracy. Cost is an important factor whenever introducing a new technology at industrial scale. AM is a cost effective technology on industrial scale due to specific build-up process that leads to significant reduction in waste materials. AM is a progressive technology which is evolving with the passage of time. With regards to the development of nanocomposite materials using AM, A system was patented in 2005 to fabricate a free form structure of a composite material comprising of CNTs, with a matrix, a discharge assembly and a composite generator with the fusing agent [19]. The author claimed that the additive manufacturing system could be used to manufacture free form structure with homogeneously distributed carbon nanotubes using variety of matrices including polymer, metal, metal alloy or ceramic. This system is particularly versatile in its nature due to the large choice of matrix materials available [19].

Nanocomposites Preparation Methods. In order to offer a particular matrix material property enhancement, such as improvement to the matrices mechanical, electrical or optical properties, it is often advantageous to have the nano particulates uniformly dispersed throughout the matrix. Achieving an adequate dispersion can be a particularly challenging process due to the Van der Waal forces present between the nano additive that result in agglomeration of the nanoparticles. To aid in the dispersion of such additives a variety of techniques have been examined over the years and the results are well documented throughout the literature. The common processing methodologies are explained in three different schemes as shown in Fig. 3.

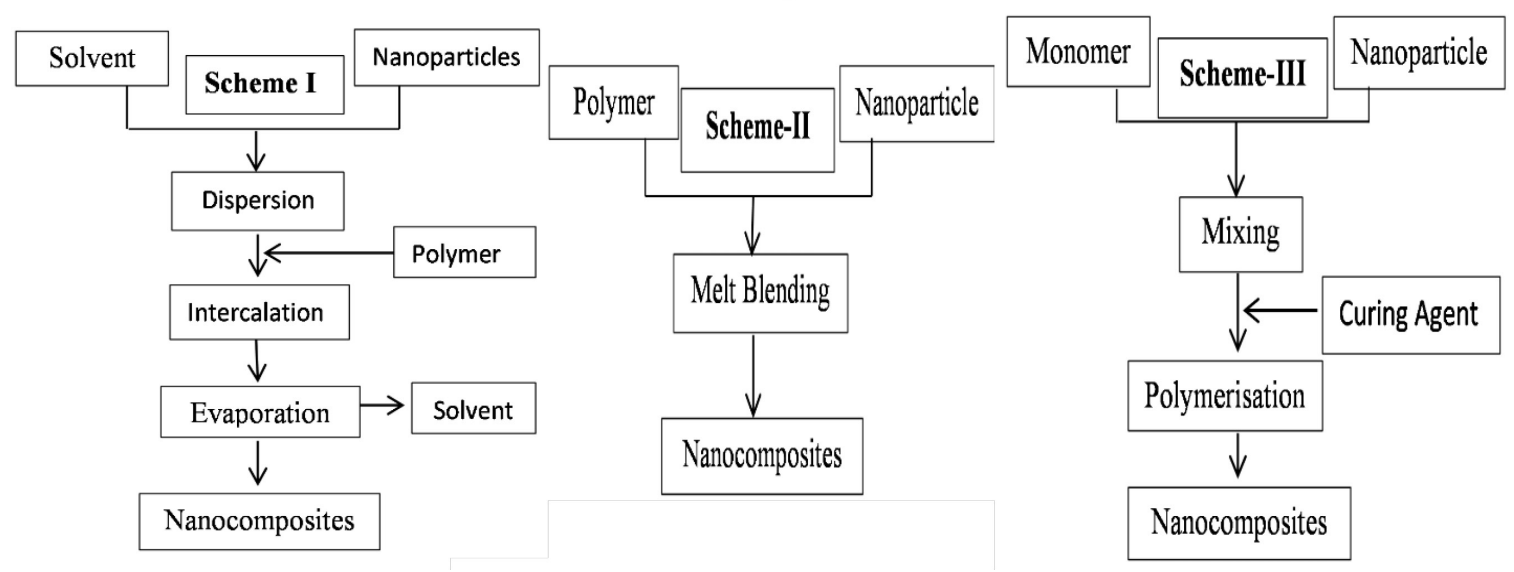

Figure 3. Nanocomposites preparation schemes. 
One of the options is suspending the nano additive materials within a solvent/polymer solution and casting a film of material containing an adequate dispersion of the nanofiller. The chosen solvent will be one which is capable of dissolving the matrix material. The additive is then added to the solution to get a particulate suspension. Simply having the nano additive within the solvent and brief mixing is not always sufficient unless there is a sufficient interaction between the solvent and the filler. Therefore an additional method is required in order to disperse the Nano particulates. The most common method in this case is sonication where ultrasonic cavitation agitates the aggregated material, breaking them apart into their individual nanoparticles. This can be used to suitably disperse the aggregates; however there are also potential drawbacks. It is possible that the nanoparticles will re-aggregate over time [20] and it is also possible to damage the nanofillers, particularly those with a large aspect ratio if they are exposed to the ultrasonic waves cavitation [21]. Damage to the filler particles is not limited just to the sonication method as melt compounding has been observed to lead to the shortening of nanotubes [22]. To further aid and maintain the dispersion within the solvent/polymer solution, surfactants can be added [23, 24].

One of the simplest techniques is to mix the material in with shearing forces. There is mechanical equipment available that can be used for this purpose such as a compounder (twin screw system) which can mix the nano additive into the polymer matrix in the melt state. Often this is combined with a die and the material is extruded into a filament, fibre or film. This can result in a good dispersion of the nanofiller particle throughout the matrix material as demonstrated by Thostenson and Chou who prepared polystyrene/MWCNT composites in a micro compounder followed by extrusion through a rectangular die [25]. Pötschke et al. made similar observations when they examined melt mixing of MWCNT with polycarbonate using a micro compounder, again observing uniform dispersions from the mixing process [26]. In both of the studies by Thostenson and Chou and Pötschke et al. the material was subsequently extruded after the mixing processing and observations showed general alignment of the nanotubes along a common axis.

Another approach is to simply mix the nanoparticle additive into a monomer. Once dispersed, the monomer is subsequently polymerised resulting in the filler being dispersed throughout the polymerized material. One must have a prior knowledge about the nature of the polymer matrix and nanoparticles before adopting a methodology. Mechanical mixing processes such as those mentioned above offer a simple approach to distributing the nanoparticles within the matrix, however there are additional methods that involve a more chemically based route. One particular example is through the functionalization of the nanofiller, a technique that involves adding side groups onto the filler particle which can promote a stronger interaction with the surrounding media, and hence a better dispersion within the matrix material. There are several methods for achieving the functionalization, examples of which are provided in a review by K. Balasubramanian etl. They examined the literature on the functionalization of carbon nanotubes and covered the various methods [27].

After achieving a uniform dispersion of nanoparticles it can be used as an input (feedstock) material into a particular AM technique. The choice of the technique is based on the nature of nanocomposites material i.e liquid or solid. For example SL will be an appropriate technique of it's a resin based nanocomposite while if nanocomposite material is a solid powder than SLS will serve the purpose. A general schematic is shown in the Fig. 4.

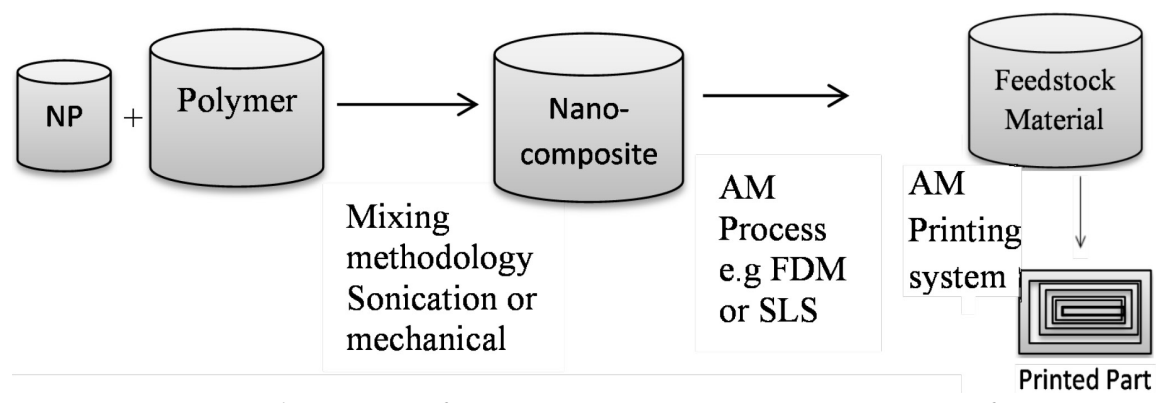

Figure 4. Schematics for nanocomposites preparation for $A M$. 
From the next section, SL, SLS and FDM techniques are discussed in the perspective of using nano structure material. A brief introduction was provided for each printing technique without involving into details as technology is evolving and so does the design. The relative data is collected and presented in a categorical way to shed light on the limitations and success of using nanocomposites into different AM techniques. After the brief introduction of each technique, the published data was presented and discussed.

\section{Stereolithography (SL)}

Stereolithography (SL) is the pioneer amongst all the AM processes and has been available commercially since 1988 [28]. The technique works on the principle of curing a liquid resin (photo curable) using a UV or IR laser. Material is deposited a layer at a time and cured in desired areas through a controlled elevated optical scanning system [29], thereby allowing for the development of a specifically shaped part, designed through CAD. An example of a typical setup of a stereolithography system is shown in Fig. 5.

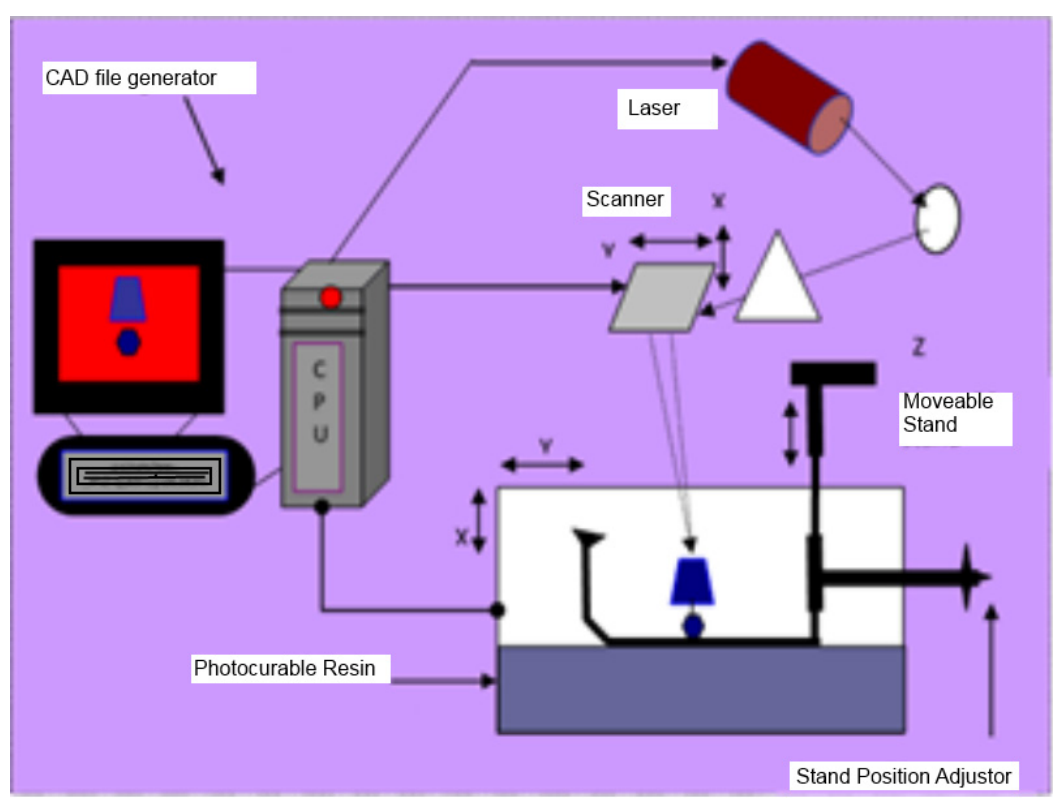

Figure 5. A schematic for a typical stereolithography system.

The knowledge of the cure kinetics is important to understand for insertion of NP into the resin for nanocomposite formation [30]. It may be possible that a portion of UV energy can be absorbed by the nanoparticle, thereby leading towards insufficient curing of nanocomposites. The preliminary knowledge about resin such as the density and viscosity is also considered valuable besides having familiarity about cure kinetics. For example, the viscosity of a UV-curing resin can affect the mobility and dispersion of NP which can lead towards lack of dispersion and affect overall desired properties. Knowledge of appropriate diluent can help to overcome this issues emerge due to high viscosity [31]. Experience with the conventional acrylate resins has shown that when SL parts are left in the laser-cured or so-called "green" state for a long time without post curing, their dimensional errors increase [32]. The longer they stay in the laser-cured state, the more inaccurate the parts become. This indicated that SL parts built in acrylate resins are not completely dimensional stable in the laser-cured state [32]. One of the first studies of nanocomposite materials with the SL process was performed by G.W. Hadipoespito et al. back in 2003, who examined the incorporation of a ceramic nanofillers silicon nitride ( $\mathrm{Si} 3 \mathrm{~N} 4)$, into a photopolymer. These particular nanofiller have impressive thermal, mechanical and semiconducting properties making it attractive for printable semi-conducting devices [9, 28].

SL and Nanoclay. There are several papers in the literature describing the inclusion of various clays into the SL process. Bentonite is a clay that is mined from the earth, and it's formed from volcanic ash thus has weathered and aged in the presence of water. In-situ preparation of hybrid 
(calcium phosphate/layered silicate) nanoparticles achieved directly within the acrylic resin using Ca-bentonite. Ca-bentonite was quantitatively intercalated by organophilic alkyl ammonium ions to yield dispersions of loosely arranged hybrid nanoparticle agglomerates without requiring separate filler preparation and special dispersing agents [33]. These hybrid nanoparticles had mean diameters in the range of a micrometer and the developed dispersions were sedimentation stable for several months at filler contents between 10 and $15 \mathrm{wt} \%$. Cured nanocomposite materials show an overall improvement of key properties of AM parts with increased nanoparticles content. An increased stiffness up to $35 \%$ in the post cured, $45 \%$ in the green state, fracture toughness up to $29 \%$, a decrease in shrinkage and distortion phenomena up to $46 \%$ was reported compared to the acrylic resin [33]. The simultaneous improvement in stiffness, toughness and building accuracy reported in the post cured and green state indicate the success of nanoclay into SL process. In one particular study S. Sharifi and etc. examined colloidal dispersions of clay nanoparticles (Laponite XLG) at $2.5 \%$ and $5 \%$ wt which were used to print nanocomposite hydrogel structures using SL that possessed designed gyroid pore network architecture [34]. The host material for the nanocomposite was a methacrylate-functionalized triblock copolymer of poly (ethylene glycol) (PEG) with poly (trimethylene carbonate) (PTMC). In the fully hydrated state, these structures had excellent mechanical properties, while the pore network structure could be maintained [34]. Organic modification of nanoclay can help to increase resin reactivity. The influence of the presence of organically modified montmorillonite (OMMT) nanoparticles on the kinetic behavior of the photo polymerizable epoxy resins was reported [35]. OMMT nanoparticles in the photo polymerizable formulation are able to increase its reactivity. Moreover, the morphological and structural analysis evidenced the presence of an exfoliated structure with an increased glass transition temperature in the nanocomposite containing OMMT $(0.3 \mathrm{wt} \%)$ in comparison to the control formulation [35]. A more recent study suggests that addition of organically modified montmorillonite (OMMT) decreased the tensile strength and elongation at break while increased the young's modulus of SL 3D printed acrylic resin nanocomposites [36]. The reduction in the mechanical properties was attributed to the UV light absorbance/scattering by OMMT that reduces the cross linking density in the nanocomposite. The lower cross linking density leads to poorer mechanical properties.

SL and Carbonaceous Nanoparticles. Carbonaceous particles include SWCNTs (single-walled carbon nanotubes), MWCNTs (multi-walled carbon nanotubes), CNFs (carbon nanofibers), graphene, diamond, fullerene, carbon blacks and graphite. These are differentiated on the basis of their structure and extra ordinary electrical and mechanical features. A complete understanding of controlled amounts of MWCNTs directly dispersed in SL resins prior to layer manufacturing is necessary to help print parts with desired features without leading to printing failure. Sandoval et al. reported enhanced tensile and fracture stresses for the case of nanocomposites of MWCNTs dispersed in an epoxy resin when compared to the pure material [37]. Even at extremely low loadings of $0.025 \% \mathrm{w} / \mathrm{v}$, improvements to the tensile and fracture stresses were observed $(5.7 \%$ and $26 \%$ respectively) with further improvements at $0.1 \% \mathrm{w} / \mathrm{v}(7.5 \%$ and $33 \%$ respectively $)$. The TEM results suggested that the MWCNT allowed for an effective load transfer from the polymer matrix to the filler and SEM characterization provided evidence that MWCNTs bridged micro cracks. MWCNTs were mixed into the photopolymer via mechanical and ultrasonic mixing; however observations of fabricated parts indicated that the nano fillers had agglomerated. Additional means for dispersing the MWCNTs such as chemical dispersion should be explored to better investigate the potential improvements provided by more effectively dispersing MWCNTs. Controlled amounts of MWCNTs were successfully dispersed in SL epoxy-based resins and complex three dimensional (3D) parts were successfully fabricated by means of a modified SL setup [38]. MWCNTs concentration of $0.05 \%(\mathrm{w} / \mathrm{v})$ increased the ultimate tensile stress and fracture stress an average of $17 \%$ and $37 \%$, respectively [38]. Uneven photo-polymerization was reported and considered an issue for the successful printing of nanocomposites as shown in Fig 6. The up side surface of the printed rectangular specimen exhibited a glossy finish (Fig. 6a), whereas the down side face exhibited a dull and rough finish (Fig. 6b). 


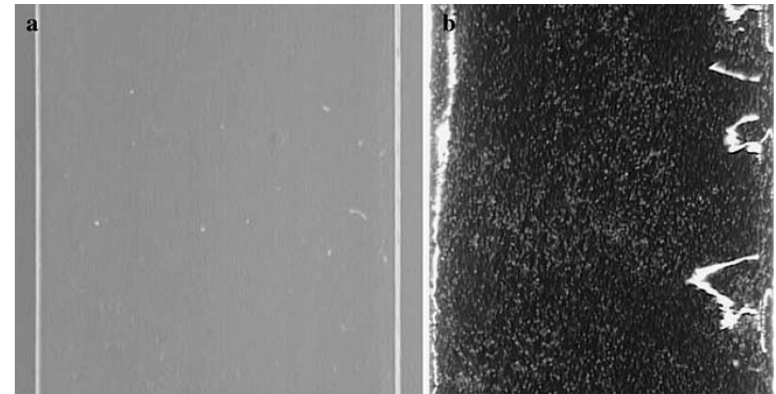

Figure 6. Pure SL epoxy resin specimen (a) the sample is characterized for being clear and it does not experience part curling. (b) MWCNTs/SL resin nanocomposite sample (notice the change in color due to the presence of MWCNTs [38].

Also, MWCNTs buckling and collapsing effects were observed in the TEM micrographs (Fig. 7) of several sections of the printed samples under tensile tests. It was found that mechanical and thermal stresses arising from the polymerization process along with the thermal effects associated with the TEM's electron beam produced this particular phenomenon [39].

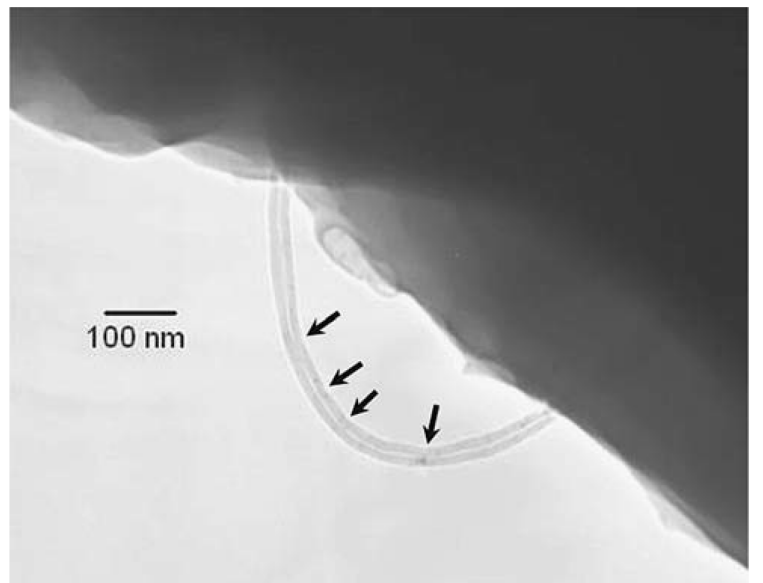

Figure 7. Buckled MWCNTs at the fracture surface of the nanocomposite, [38].

Nanocomposites based on acrylated polyurethane resin with the inclusion of MWCNTs and hydroxyapatite nanoparticles were developed [13]. A higher tensile stress was observed, 14.7\% in the case of MWCNTs and four orders higher for hydroxyapatite nanoparticles, as compare to pure acrylated polyurethane. In addition to the improved mechanical properties, a four order higher electromagnetic shielding effect was achieved for the case of resin/MWCNTs nanocomposites with the increases in the thickness/number of layers [13]. Complex three-dimensional (3D) structures were printed using graphene oxide by stereolithography with good combination of strength and ductility. With only $0.2 \%$ GOs, the tensile strength is increased by $62.2 \%$ and elongation increased by $12.8 \%$ [40]. An increase ductility of the 3D printed nanocomposites was measured and attributed to increased crystallinity of GOs reinforced polymer nanocomposite. Figure 8 shows mechanical tests performed in the study [40]. 

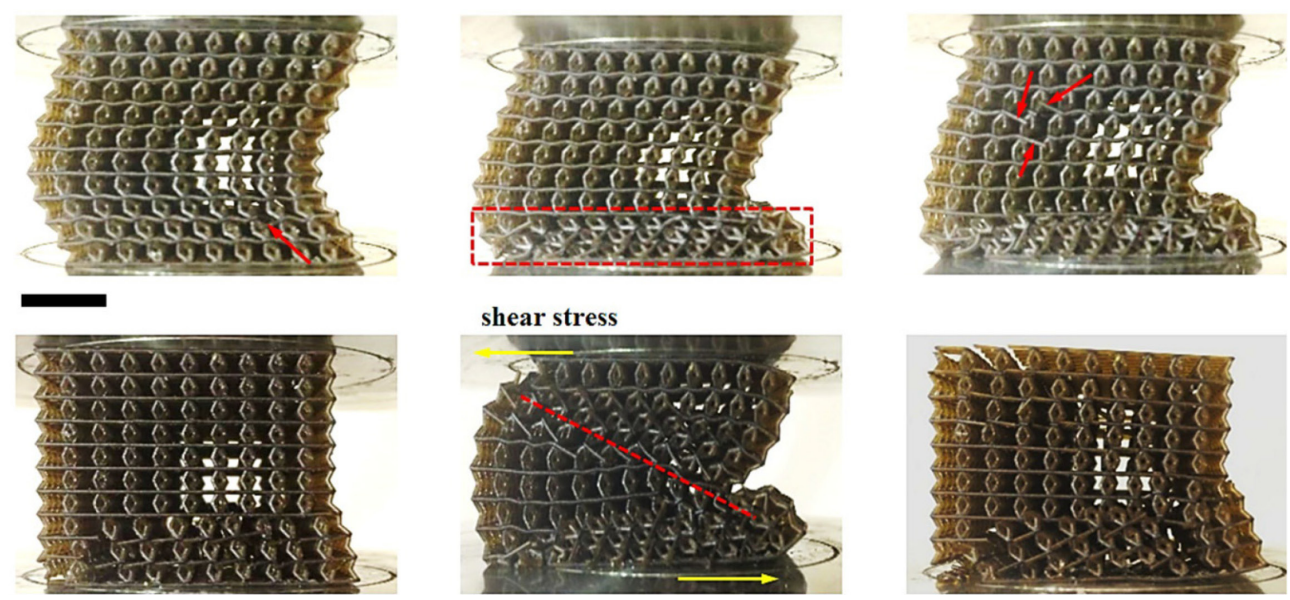

Figure 8. Various failures in GOs truss structure under compression with time sequence. (a) First failure at the truss node. (b) Truss deformation concentrated in the bottom two layers. (c) Further failure at some other truss node. (d) After relief of $20 \%$ compression, truss structure partially recovered. (e) Shear band generated by the shear force for 40\% of compression. (f) After relief of 40\% compression. Scale bar: $10 \mathrm{~mm}$ [40].

SL and Ceramic Nanoparticles. Stereolithography was used in forming the composite materials, where the feasibility of mixing the nano sized ceramic $\left(\mathrm{Si}_{3} \mathrm{~N}_{4}, 30 \mathrm{~nm}\right)$ with a photopolymer was analyzed. The nanocomposite was obtained by ultrasonic mixing of the transparent photopolymer with the nanoparticles $\left(\mathrm{Si}_{3} \mathrm{~N}_{4}\right)$ and SL was utilized to fabricate a micro-gear (Fig. 9). Examination of the micro-gear using optical microscope techniques revealed a uniform dispersion of nanoparticles $\left(\mathrm{Si}_{3} \mathrm{~N}_{4}\right)$ in the fabricated micro-gear [41]. Their results suggested nanoparticles within the microgear were uniformly dispersed. Rise in viscosity were reported due to nanoparticles. A methodology is required to reduce viscosity rise caused by NPs insertion.

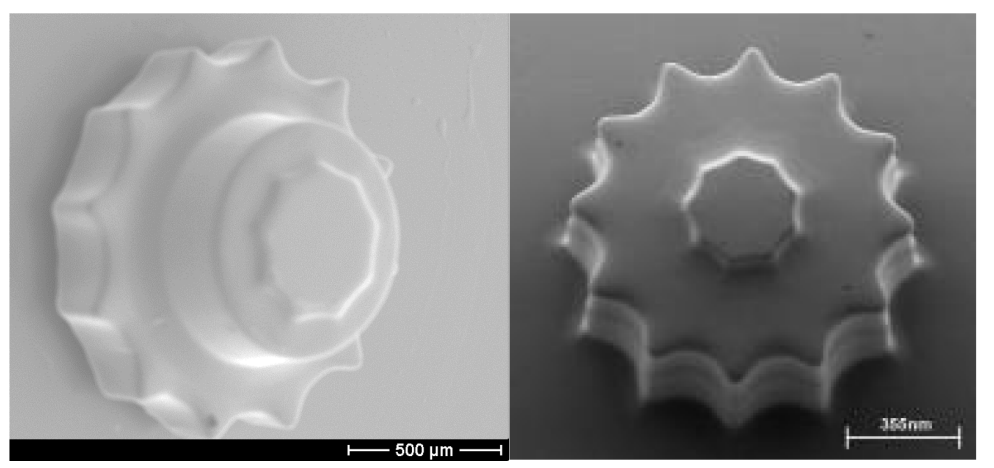

Figure 9. SEM pictures of 3D microgears, courtesy of [41].

Hydroxyapatite is a particularly important ceramic material for use in biomedical applications due to its chemical structure and properties being similar to that of bone mineral. Nanocomposites containing photocrosslinkable diacrylate resin of Poly (D, L-lactide) (PDLLA) encapsulating hydroxyapatite (HA) nanoparticles were prepared to fabricate porous scaffolds using streolithography. An increase in the viscosity of the resin was reported with the increasing content of ceramic component. In order to counteract the effects of the increase in viscosity, a non-reactive diluent N-methyl-2-pyrollidone (NMP) was added as to allow processing by SL [42]. The elastic modulus of the nanocomposite PDLLA/HA network materials increased with increasing nanofiller content. A complete agreement between designed and prepared structures was reported. Although some aggregation of the particles occurred, it was shown that the ceramic component remained well dispersed in the polymeric matrix [42]. In another attempt, a series of novel 3D bone matrices of differing geometry were successfully printed and reported using a stereolithography based 3D printing technique, to provide a more biomimetic microenvironment for breast cancer cell growth. The printed nanocomposite scaffolds proved cell proliferation and physiological model with the inclusion of HA nanoparticles [43]. Compared with conventional 2D cell culture, breast cancer cells growing on the $3 \mathrm{D}$ scaffold exhibited a greater migration capacity. Co-culture of human bone 
marrow mesenchymal stem cells (MSCs) with cancer cells on the 3D matrix resulted in increased spheroid colony formation. Therefore, this $3 \mathrm{D}$ scaffold may provide a promising model to study the behaviour of breast cancer bone invasion and the evaluation of new therapies. The printed bone matrix presented a well-defined square architecture, and high magnification SEM images revealed a homogenous dispersion of HA nanoparticles within the entire matrix. Cell proliferation was significantly increased on bone matrices containing HA nanoparticles.

In another study utilizing metallic nanoparticles, 3D dielectric lattices were designed by [44] using acrylic diamond structures with alumina nanoparticles dispersion through use of SL. In this approach, nanoparticles of $40 \%$ vol. were used to reinforce the material to that of ceramic slurry. By the careful optimization of process parameters like de-waxing and sintering, dense alumina micro lattice structures were fabricated successfully. The sintered photonic crystal of alumina formed a complete band gap at the terahertz region from 0.35 to $0.49 \mathrm{THz}$. Localized modes were obtained by introducing a point defect of air cubic cavity and a plane defect between twinned diamond structures, which were reported in good agreements with the suggested simulation results. It is expected that these three dimensional photonic band gap structures can be applied to control terahertz waves [44].

In a wider context, SL is also integrating with other technologies for the product quality enhancement. For example in electronics, a Capacitor with complex three dimensional structures were 3D printed using SL process. The fabrication method relies on embedding high dielectric particles (PZT) in a photo curable polymer resin, decorated with Ag coating. The calculated specific capacitance of the $3 \mathrm{D}$ printed capacitor was reported as $63\left[\mathrm{Fg}^{-1}\right]$ with current density of $0.5\left[\mathrm{Ag}^{-1}\right]$. The dielectric permittivity of composite (Flex/PZT@Ag) as high as 120 at 100 [Hz] with 18 vol\% filler, which is about 30 times higher than that of pure Flex. Furthermore, the dielectric loss is as low as 0.028 at $100 \mathrm{~Hz}$ [45].

SL and Silica Nanoparticles. A novel family of optically transparent acrylic nanocomposites containing up to $30 \mathrm{wt} \%$ silica nanoparticles with an average diameter of $20 \mathrm{~nm}$ was developed for applications in SL [46]. The uniform dispersion of nanoparticles significantly improved toughness/stiffness-balance of the photo polymerized and post cured nanocomposites. An increased stiffness, $\approx 32 \%$, without encountering the embrittlement and reduced shrinkage was observed in the printed parts. The viscosities and transmittance marginally affected by silica nanoparticle concentrations up to $17 \mathrm{wt} \%$ at the cost of slight increase in the exposure times required for photo polymerization [46]. Moreover, the building accuracy is increased significantly with increasing content of nano silica. Different methods can be used to decrease viscosity and delay shear thickening to the higher shear rates. These include heating the dispersions, low filler loading and using optimum rheological conditions for dispersions. In a recent approach, transparent fused silica glass components using stereolithography 3D printers at resolutions of a few tens of micrometres [47]. The type of resin also affect dispersion of nanoparticles and hence the print quality. Amorphous silica nanoparticles with a mean diameter of $40 \mathrm{~nm}$ were dispersed in a monomeric matrix mainly consists of the monomer hydroxyl ethyl methacrylate (HEMA), which allows the dispersion of high amounts of silica nanoparticles owing to the formation of a solvation layer, without using further additives [48]. The nanocomposite was then shaped with stereolithography using free radical polymerization (Fig. 10), resulting in the so-called 'green part'. The resulting green part can be further polymerized thermally or by an additional floodlight-exposure step. The shrinkage of the part during the sintering process is isotropic and dependent on the solid loading [47]. Modification of silica nanoparticles can help to overcome particles homogeneous dispersion and thereby making nanocomposite material mechanically strong. The shape of the filler particles also plays an important part to improve mechanical properties of the fabricated parts using SL. In a recent attempt, addition of $5 \mathrm{wt} \%$ of sphere-like organically modified nano $\mathrm{SiO} 2$ increased the tensile strength and modulus of 3D printed materials by $20.6 \%$ and $65.1 \%$ respectively [36]. 


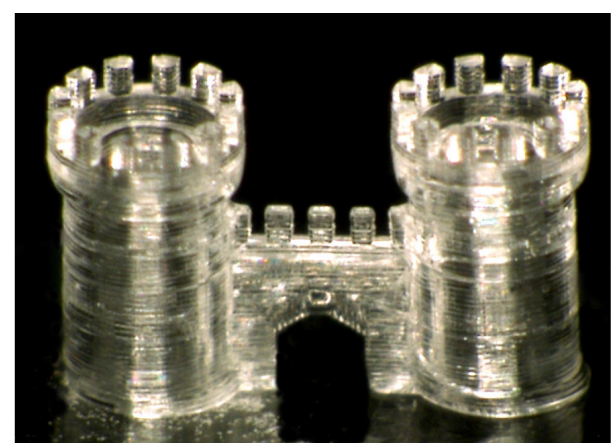

Figure 10. Microstructure of fused silica glass using SL of a hollow castle gate, (scale bar, $270 \mu \mathrm{m})$, courtesy of [47].

In contrast to organic polymers, curable inorganic polymer, for example (polyvinylsilazane with 2-isocyanatoethyl methacrylate), offers high photosensitivity when used for the fabrication of 3D patterns. It was reported that after pyrolysis the original designed shape shrank in an anisotropic fashion, resulting in a pyramid like structure. By adding silica nanoparticles ( $\sim 10 \mathrm{~nm}$ diameter $)$ to the material it yielded a significant reduction in the dimensional deformation [49]. In particular, microstructures containing $40 \mathrm{wt} \%$ silica nanoparticles exhibited a relative isotropic shrinkage. The results had particular promise for developing devices for a variety of applications in the fields of tribiological microelectromechanical systems (MEMS) and chemical resistant microfluidics [49].

SL and Metallic Nanoparticles. A nanocomposite was developed containing a photopolymer and magnetic nanoparticles (ferrite) with loadings up to $15 \mathrm{wt} \%$. The filler particle was $\gamma-\mathrm{Fe}_{2} \mathrm{O}_{3}$ nanoparticles with a 7-nm and coated by amorphous- $\mathrm{SiO}_{2}$. A small scale magnetic rotor $(6 \mathrm{~mm})$ was prepared using the composite material through SL, to which it was included in a U-shaped channel for a viscous micropump [50]. Fluid transport using the viscous micro-pump was demonstrated with the ability of cell sorting. The intended use for this nanocomposite material was for applying magnetically driven micromachines. The magnetic driving method is easy and low-cost, making it useful for micro total analysis systems and medical diagnosis. In terms of functional devices, a flow sensor was fabricated using nanocomposite based on an acrylic oligomer (similar to 1,6 hexanediolethoxylate diacrylate), cross-linking agents (dipentaerythritol pentaacrylate and propoxylated trimethylpropane triacrylate), a photoinitiator (2-benzyl-2-(dimethylamino)-4'morpholinobutyrophenone) and magnetite $\left(\mathrm{Fe}_{3} \mathrm{O}_{4}\right)$ nanoparticles (avg. diameter $50 \mathrm{~nm}$ ). The fabrication processes were performed at ambient light to avoid premature polymerisation of the materials. A viscous resin was suggested to overcome problems occurred due to aggregation and sedimentation of large size magnetic nanoparticles to get a uniform dispersion. It was observed that presence of the magnetite particles disrupts the cross-linking of the resin matrix reducing the overall strength of resin [51]. Appropriate surfactants can help to break aggregates of nanoparticles. Surfactants play a crucial role to achieve desired functionality from printed parts. Dispersions of $\mathrm{TiO}_{2}$ and $\mathrm{Fe}_{2} \mathrm{O}_{3}$ nanoparticles in solvent free, UV curable media (2-hydroxy ethyl acrylate (2-HEA), 4-hydroxy butyl acrylate (4-HBA) and polyethylene glycol 200 diacrylate (PEGDA) with 17-19 vol\% have been produced with the aid of comb-polyelectrolyte surfactants. Dispersions were successfully UV cured to produce $\mathrm{TiO}_{2}$ /polymer composites, however it was observed that $\mathrm{Fe}\left(\mathrm{C}_{2} \mathrm{O}_{4}\right) \cdot 2 \mathrm{H}_{2} \mathrm{O} /$ polymer nanocomposite cannot be solidified due to high UV-vis absorption of $\alpha$ $\mathrm{Fe}_{2} \mathrm{O}_{3}$ nanoparticles and could only be cured thermally [52]. A recent study described results of several experiments carried out to investigate the feasibility of using commercially available SL lasers for curing conductive ink traces. The conductive ink contains silver nanoparticles while no information was provided for the particular resin employed for the purpose of SL. Experiments were performed using two laser wavelengths, several inks, and different scanning dynamics (scan speeds, laser power, and scanning locations) to determine the conditions for most effective in situ laser curing of DP-dispensed conductive ink traces within a SL system. Experiments determined that thermal post-curing of partially cured ink traces enhances the conductivity of an embedded trace regardless of initial partially-cured state, thereby eliminating the need for complete laser curing prior to embedding the trace and thereby reducing overall fabrication time [53]. Curing ink 
traces at high laser power and slow scan speeds with the laser beam located on the substrate adjacent to the ink channel resulted in the most effective ink curing but resulted in discoloration of the ink and/or charring of the SL substrate.

SL and Semiconducting Nanoparticles. Semi-conductor based nanomaterials have been used in composites due to their wide array of applications. K.K. Jang et al. reported printing resin mixtures (acrylate and urethane acrylate resins) containing quantum dots for fabrication of 3D microstructures. The goal was to print photo-pattern able display devices contained red, green and blue (RGB) quantum dots. Core only and core-shell quantum dots (QDs) of (CdS/ZnS), CdSe/ZnS and $(\mathrm{CdSe} / \mathrm{ZnSe})$ were functionalized with a photosensitive monolayer to make them photo-pattern able using SL. Core-shell type QDs was reported to have better photoluminescence properties as compare to core only QDs upon exposure of UV-light. The 3D microstructures fabricated were found to have uniform dispersion of RGB QDs. The hybrid nature of QDs makes them suitable for solution processing on both inorganic and organic substrates [54]. In the work of Frank Deubel et al. a novel method for the preparation of polymer/semiconductor nanocomposites is presented. The nanocomposite is directly prepared from a suspension of nano-crystalline silicon (nc-Si) in bulk vinyl monomers (acrylates) and focused heating of the nc-Si by irradiation with a pulsed laser at $532 \mathrm{~nm}$ wavelength. The nc-Si converts the energy input in the form of laser irradiation into thermal energy that triggers the polymerization of acrylic monomer to form the cross-linked organic matrix. Layer thicknesses of up to $250 \mathrm{~mm}$ and well-resolved patterns were readily obtained [55]. Reaction conditions are affected by the nc-Si content of the monomer-nanoparticle dispersion. A thermal initiator is used to compensate the relatively slow polymerization reaction. This also significantly improved the pattern morphology as well as the realizable nanocomposite film thickness to around $600 \mathrm{~mm}$. The laser-induced thermal polymerization technique can be employed for a broad range of novel materials which demands high refractive index nanocomposites coatings [55].

\section{Selective Laser Sintering (SLS)}

Selective laser sintering (SLS) systems create complex 3D models through the use of a laser system that fuses powdered material in selective areas controlled through CAD, in a layer by layer fashion [28]. $\mathrm{A} \mathrm{CO}_{2}$ laser serves as a heat source to fuse the powder up to the melting point, consequently a bonding occur between the fused layer and the previous layer. An illustration of the SLS system is provided in Fig. 11. There are inherent limitations in using nano particles in powderbased RP techniques such as SLS because it will decrease the tap density and process-ability and the reduction in the tape density [56]. However, nano-structured powder of micron size can be used for nano effect $[11,57]$. Presence of nano particles into polymer inhibits movement of polymer macromolecules and increases tensile modulus and strength of the polymer without reducing its impact resistance. However, a higher volume fraction is unsuitable as it decreases final green density [11]. In order to cover wide range of materials, the laser processing of powder materials in SLS calls on various consolidation mechanisms: the binding of polymers, metals, ceramics and their mixtures or composites varies substantially with initial powder composition, the final aimed material composition and the aimed material structure (aimed porosity or density, microstructure, properties, etc.). Some process variants may apply post-processing after SLS: in such case, the selected layer consolidation mechanism should account for the post-process as well: e.g. need for open porosity if post-infiltration is applied [58]. It has been observed from literature that substantial amount of research focused on polyamide as the matrix material with carbonaceous or clay nano additives. 


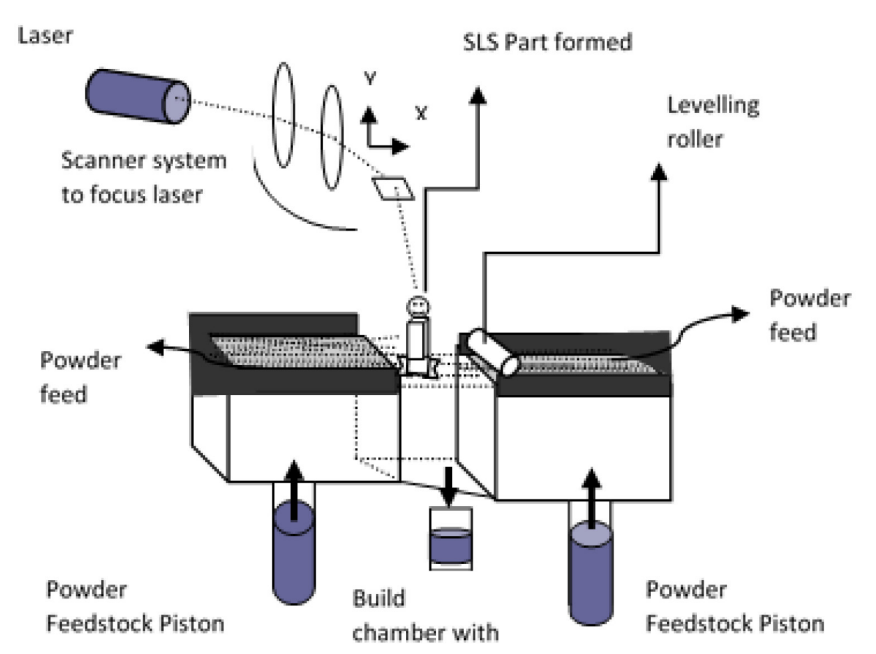

Figure 11. Illustration of selective laser sintering system.

SLS and Clay Nanoparticles. One of the earliest nanocomposite materials, containing clay nanoparticles and PA-6 was reported by [59] for SLS application. A comparative study of sintering behaviour such as part-bed temperature and laser power between the nanocomposite and standard polymer were investigated. A higher porosity (Fig. 12) was reported as compared to standard polymers due to sintering effects [59]. Porosity may come from both the clay effect and poor powder compaction. The porosity is an indication of the nanoparticles interaction with the polymer chain which demands some modification in the SLS process to use this composite material in the additive manufacturing techniques. The sintering of PA-6/nanoclay composite required both higher part-bed temperature and laser power when compared to the neat PA-6 [59]. The nanocomposite exhibited slightly higher storage modulus than neat PA- 6 . The small difference of storage modulus show that clay does not prevent molecular motion efficiently or caused by insufficient amount of clay contents or the clay may not exfoliated well[59].

a)

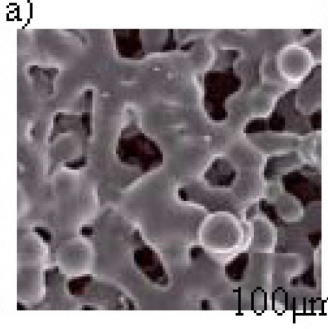

b)

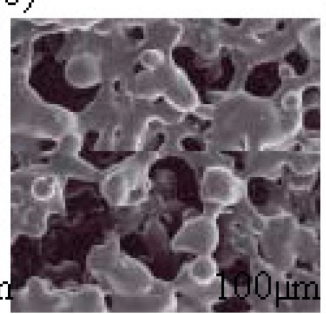

c)

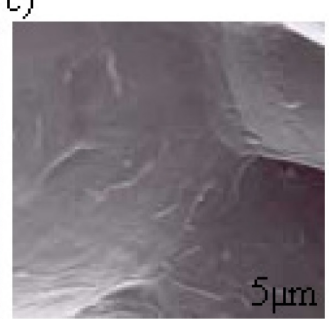

Figure 12. Sintering result of a) polycarbonate surface morphology $(x 45)$ b) nanocomposite surface morphology (x45) and c) morphology near the pore (x2000) [59].

Further studies were conducted [11] to study sintering characteristics and thermal properties of nanocomposite containing nanoclay. The material's viscosity and its mechanical properties were increased due to reinforcement effects from the nanoclay. Sintered nanocomposite powders showed lower final density than the standard polymer due to increased resistance to low shear rate deformation. This would perhaps indicate a limitation on nanoclay content as the higher nanoclay content may not be applicable in the SLS process due to its low final density and increased viscosity [11]. The properties of the desired part depend on the nature of filler used in the powder matrix. Injection molded polymer pellets with three types of nanoparticles, chemically modified montmorillonite (MMT) organoclays, nanosilica, and carbon nanofibers (CNF), were used to fabricate PA-11 nanocomposites for SLS. Mechanical, thermal and flammability tests suggested that PA-11/CNF nanocomposites exhibited the best overall properties for the SLS process and unsuccessful for PA-11/clay nanocomposites [60]. A very small amount $(\sim 0.5 \% \mathrm{wt})$ of fumed silica additive was suggested to enhance powder flow and facilitate the SLS process [60]. Polymer matrix (PA-6) with Yttrium stabilised zirconia (YSZ) and Benton166 alkylaryl ammonium hectorite clay 
(B166) particles were prepared using SLS by [61]. A good dispersion of the YSZ and Benton166 clay was achieved in the PA6 matrix, following solution blending, and spray drying techniques. The measurements of the tensile strength showed a reduction for both nanocomposite materials compared to the unfilled PA6 material [61]. This was caused by sintering leading to voids formation which reduces density and strength. Most of the voids for the spray dried material are spherical in shape and bigger than those in the as received PA6 as shown in Fig. 13. This suggests that the cause could be from the trapped gases generated from residual solvent from the spray drying being driven off during laser sintering [61]. It was reported that spray drying process has an adverse effect on the base mechanical properties.

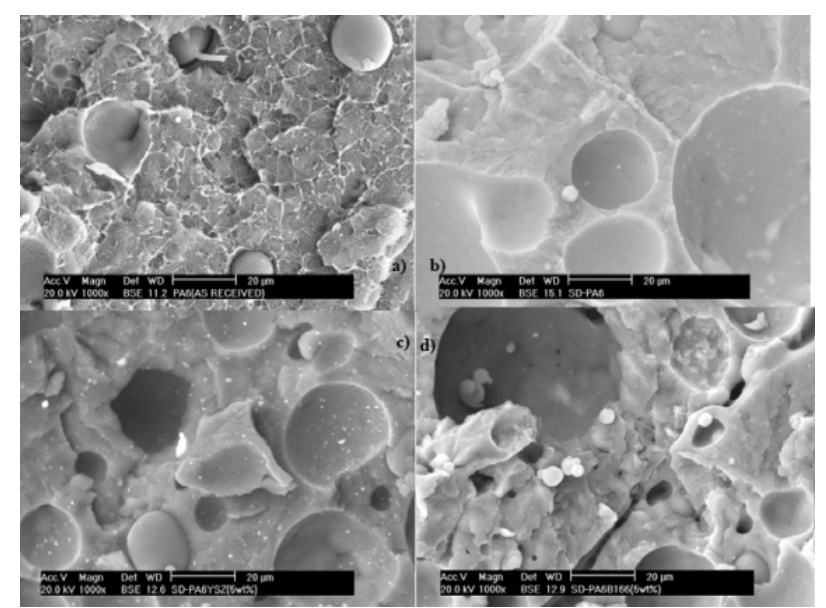

Figure 13. SEM images of tensile fracture surface of as a) received PA6, b) Spray dried PA6, c) Spray Dried PA6/YSZ (5wt\%) and d) Spray Dried PA6/B166 (5wt\%) nanocomposites [61].

Different methods are used to eliminate the voids to print parts with enhanced mechanical features compare to traditional manufacturing. Greco et al. analyzed the sintering behavior of PA6 powders and PA6 nanocomposites using modified dimethyl benzohydrogenated montmorillonite as nanofiller by thermomechanical analysis (TMA), in rotational molding for potential industrial applications. $4 \% \mathrm{wt}$ loadings of the nanoclay were used with and without thermal stabilizer (potassium halides 3\%) in the PA6 matrix. The sintering of PA6 and PA6 nanocomposites was reported in two different steps, namely powder coalescence and void removal. The sintering of the PA6 nanocomposites results in a degradation phenomenon leading to gas formation in the molten polymer. The temperature difference between the end set sintering and the onset degradation indicated that powder coalescence was influenced by the viscosity evolution of the matrix, whereas void removal was influenced by the gas diffusivity inside the molten matrix. The PA6 nanocomposites in this case showed a very narrow processing window, not suitable for sinteringbased processes. The use of thermal stabilizer involves a significant delay of the degradation of the material, which involves a broadening of the processing window at very high value (about $80 \mathrm{~K}$ ), making stabilized PA6 a candidate material for sintering-based processes [62]. The feasibility of processing polylactic acid (PLA) and a PLA/nanoclay nanocomposite by selective laser sintering (SLS) were reported [63]. Their findings suggested that nanocomposites required a relatively higher processing powder bed temperature compared with neat PLA, ultimately led to higher flexural properties as shown in Fig. 14. Moreover, in the laser energy input range where the polymer does not degrade, higher laser energy input can lead to improved mechanical properties of sintered part. It was also reported that the parts started to curl and the build failed at relatively high laser power for laser input energy [64]. 

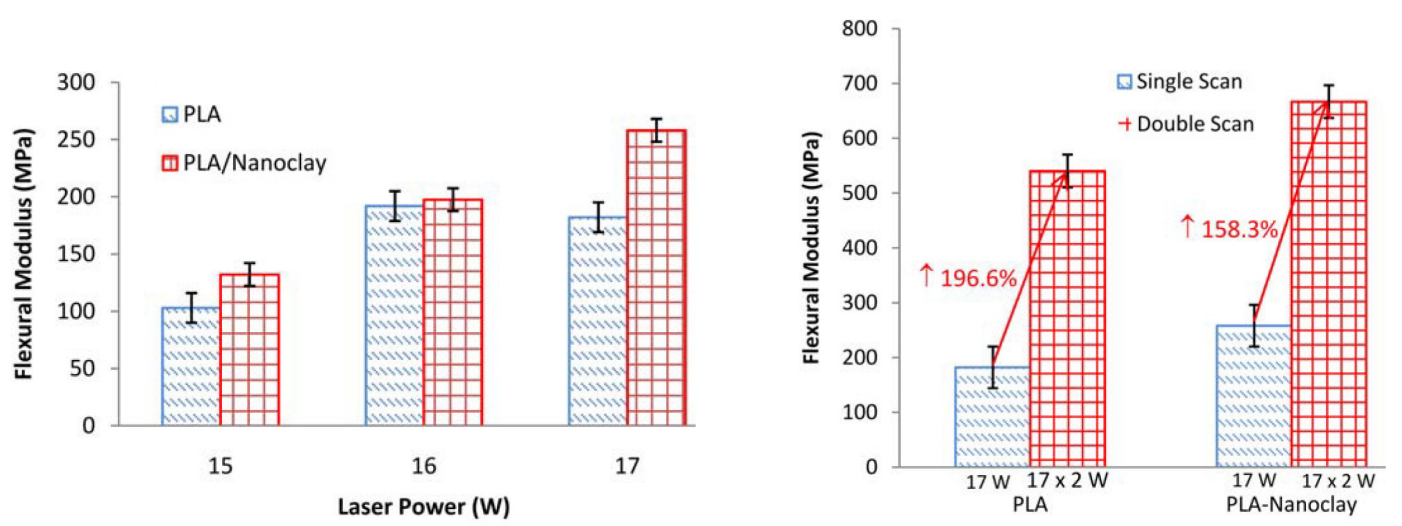

Figure 14. Variation in flexural modulus of PLA and PLA/nanoclay with respect to Left) laser power and Right) laser scan type for PLA and PLA/nanoclay [64].

SLS and Carbonaceous Nanoparticles. CNTs and graphene, with high electrical conductivity and high mechanical strength, have remarkable impact on host material. Example of the research and observations made using carbon based nanofillers in the SLS process include efforts by G. V. Salmoria et al. who prepared specimens using nanocomposites containing MWCNTs with PA12 matrix. The average diameter and length of the MWCNTs was $140( \pm 30) \mathrm{nm}$ and of $7( \pm 2) \mu \mathrm{m}$. The samples exhibited a higher flexural modulus, ultimate strength and storage modulus for the nanocomposites when compared to pure PA12 specimens with the addition of $0.5 \%$ wt of MWCNTs [65]. The fatigue test showed an improvement in the composite stiffness with the addition of MWCNTs, and improving dynamic mechanical properties of the PA12/MWCNTs composite. In term of sintering, laser power and bed temperature are relevant parameters one has to consider during the printing process as filler particles either can quench the supplied energy or facilitate in transfer to the neighborhood. The thermal influence of CNT on the PA12 laser sintering process was assessed by physical experiments and three dimensional computer modeling. The heating and cooling stages of the laser sintering process were addressed with a continuous moving laser beam [66]. A double ellipsoidal heat flux model was applied to input a three dimensional continuously moving volumetric laser heat source. The predicted results of three dimensional temperature distributions (Fig. 15) suggested that the laser heat was conducted wider and deeper in the PA12-CNT compared to PA12, which was due to the greater thermal conductivity of PA12CNT [66].

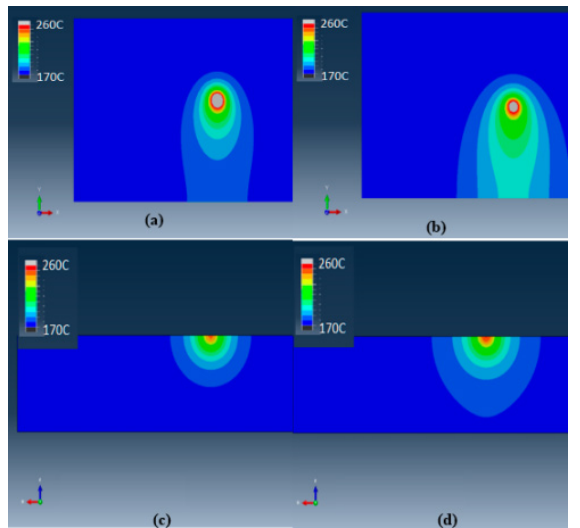

Figure 15. Temperature distribution of (a) PA12 and (b) PA12-CNT at x-y plane. Modelling of melting depth of laser sintering in (c) PA12 and (d) PA12-CNT nanocomposites, [66].

In conjunction to the sintering and heat flow in the (CNTs/PA12) nanocomposites powder a dual experimental-theoretical method was proposed by S. Yuan et al. to evaluate the process-ability and predict the processing parameters of developed nanocomposite (CNTs/PA12) powders. The composite powders exhibited improved heat conduction and heat absorption compared with virgin polymer powders, and the stable sintering range of composite powders was extended and found to be favorable for the sintering process [67]. This was attributed to the CNTs that facilitate heat absorption allowing the polymer powders to fully melt and fuse effectively within a short time 
domain. Moreover, CNT fillers can remain at the powder boundary and form a 3D network within the matrix due to the pressure free and superfast heating-cooling process unique to laser sintering. Such a strengthening mechanism is helpful to overcome the limited ductility of laser-sintered parts and improve their strength and toughness [67]. A small amount of CNT was incorporated into the PA11 matrix, which was then processed by SLS successfully. Results showed that the toughness of the laser-sintered PA11 nanocomposite was improved significantly. Based on the observation and experimental investigation, the toughening effect was contributed to the deflection and distortion of the cracks when propagating inside the nanocomposites matrix, and the crack-bridging, CNT pullout and CNT break which also absorb additional energy by hindering crack propagation [68]. In addition, the increased crystallinity and smaller crystal size induced by the CNT would also benefit the toughness to some extent [68]. TEM showed that MWNTs were well dispersed into the PA11 matrix when processed using a planetary mixer followed by twin screw extrusion [69]. It was suggested that better dispersion can be achieved by using a more aggressive screw design. MWNTs enhanced the mechanical properties (except tensile elongation at rupture), thermal stability, and electrical conductivity properties of the PA11. An elastomeric component was suggested to improve the tensile elongation at rupture. Moreover, they observed a three order decrease in resistivity compared to pure PA11 samples with $1 \% \mathrm{wt}$ addition of MWCNTs. The comparisons of the results indicated an enhancement in electrical conductivity and encouraged using this powder formulation for SLS prototype applications [69]. All PA11-MWNT nanocomposites failed the flammability test. It has been demonstrated that thermal and flammability can be enhanced substantially as long as synergism is established between the MWNTs and conventional flame retardant additive in the polyamide matrix [70]. Recently, different mechanical mixers were used to achieve homogenous powder-powder mixture of nanocomposites containing graphene and PA-11. The measured resistivity values fit in the upper region defined by electrostatic dissipative polymers due to lack of uniform dispersion and insufficient exfoliation of graphene nano platelets (GNP) [71]. Twin screw extruder with appropriate surface functionalization of NGPs can help to improve dispersion and reduce aggregate size and number of aggregates.

The literature suggests, PA was mostly used in different studies. On contrary to use PA, polyether ether ketone (PEEK) was used in a recent study [72]. PEEK is a colourless organic thermoplastic polymer in the polyaryletherketone (PAEK) family, used in engineering applications. Hot stage microscopy reveals a 20[s] delay in the onset of GNP/PEEK nanocomposite coalescence in comparison with plain PEEK. This is a very important observation for laser sintering, as it will influence the build strategy and specific parameters (e.g. time between layers deposition, multiple exposures) [72]. The thin films exhibited enhanced mechanical properties within $0.1-0.5 \%$ wt GNP, whereas the electrical conductivity properties of the nanocomposite films were significantly improved by the addition of GNP within 1-5\%wt. [72].

Carbon nanofibre fillers have also been used to prepare composite materials. Like carbon nanotubes, CNFs are also getting attention to use as potential filler particles into polymeric matrices. In another study [71], CNFs (maximum of 3\% wt) were used in the production of nanocomposites with PA-12 as matrix material. The CNFs possessed diameters $60-150 \mathrm{~nm}$ and lengths of $30-100 \mu \mathrm{m}$. The nanocomposite was prepared using melt mixing followed by cryogenic milling. SLS process was used to print parts employing the nanocomposites. It was observed that the nanofibres were well dispersed within the polymer matrix thereby enhancing the storage modulus (22\%) compared to the base material [73]. However, the cryogenic fracturing method did not produce powder with suitable morphology for laser sintering. Angular particle morphology was observed compare to the regular, near-spherical particles of the AS-PA12 (as received powder). A novel method based on selective laser sintering (SLS) process is proposed for the first time to prepare complex and high-performance carbon fibres/polyamide12/epoxy (CF/PA12/EP) ternary composites. There are two main mechanisms for good interfacial adhesion between the CFs, PA12 and EP matrix. One is the enhanced mechanical interlocking owing to the surface modification of the thin layer of PA12 and the other is the chemical interaction to form hydrogen bonds and covalent bonds on the interfaces [74], Fig. 16. 


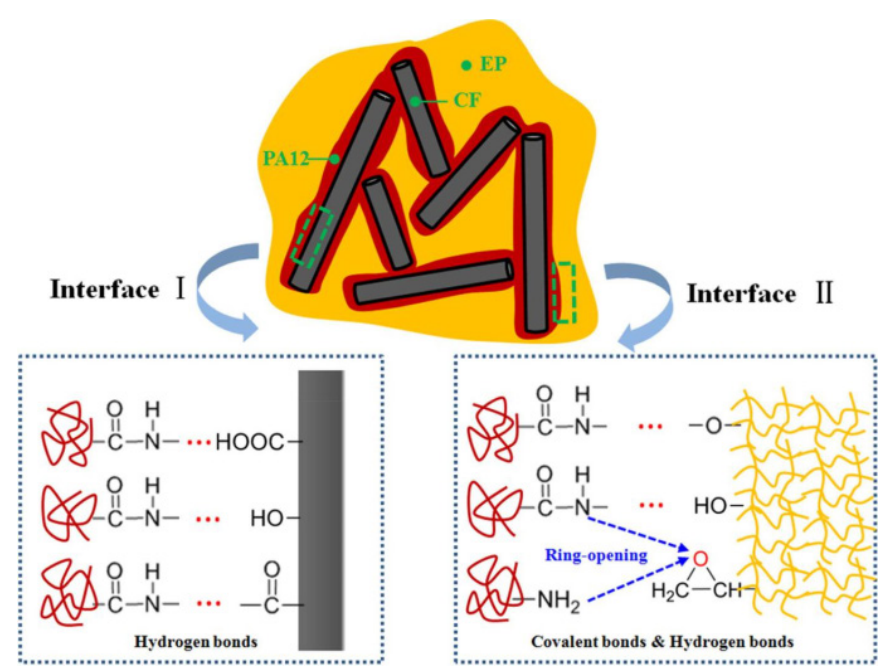

Figure 16. Sketches of the ternary-nanocomposite and the chemical reactions at the interfaces, [74].

Compression molding (CM) and selective laser sintering (SLS) were compared in terms of fabrication process, electrical conductivity and flexural strength for bipolar plates used in to the Proton Exchange Membrane (PEM) fuel cells. Natural graphite (NG), synthetic graphite (SG), carbon black (CB), and carbon fiber (CF) were used as the constitutive materials for both processes, with epoxy resin employed as the binder matrix. The results show that the trends of electrical conductivity variations versus changes in the volume fractions of SG and CF are the same for the $\mathrm{CM}$ and SLS processes; however, increasing the volume fraction of nano-size $\mathrm{CB}$ increases electrical conductivity in the CM process but decreases electrical conductivity in the SLS process [75]. The flexural strength improves significantly by adding SG and CF and increases slightly by increasing the $\mathrm{CB}$ ratio in the CM process. For SLS-fabricated parts, only CF can improve the mechanical strength, while SG and CB reduce the flexural strength of the composite plates [75]. Athreya et al. did remarkable work in context to electrical conductivity of nanocomposites containing polyamide (PA) with carbon black (CB) as a filler particle. Nanocomposite were observed to have 5 orders of magnitude higher electrical conductivity as compared to neat PA at just $4 \% \mathrm{wt}$ concentration of $\mathrm{CB}$, which is indeed a very low concentration and described the success of the SLS process for nanocomposite synthesis [76].

SLS and Ceramic Nanoparticles. Additive manufacturing has potential for use in the biomedical field, for example producing porous or lattice structure based parts with enhanced mechanical properties. Solid gage parts and scaffolds with periodic porous architectures were reported (2012) using $0-30$ vol.\% hydroxyapatite (HA) nanoparticles with polycaprolactone (PCL) through optimization of the SLS process. Hydroxyapatite (HA) with calcium apatite having molecular formula $\mathrm{Ca}_{10}(\mathrm{OH})_{2}\left(\mathrm{PO}_{4}\right)_{6}$ and an average particle size of $45 \mu \mathrm{m}$ was used. Through optimization of the SLS process, the compressive moduli for the solid gage parts and scaffolds are the highest reported in the literature for additive manufacturing [77]. The compressive effective stiffness tended to increase as the loading of HA was increased and the designed porosity was lowered. In the case of 3-D porous scaffold, the compressive modulus was reported as more than doubled from 14.9 to 36.2 $\mathrm{MPa}$ with the incorporation of hydroxyapatite (HA) [77]. The HA nanoparticles acted as an anti-caking agent at temperatures close to the melting temperature for the neat polymer [77]. The significantly growing use of AM has attracted the biomedical field through the fabrication of innovative parts, characterized by lightness and good mechanical properties. The correlation between strength parameters and relative porosity of parts obtained through SLS were reported recently [78]. A 1D elasto-plastic finite element model was used to compare with the experimental results. The method proved to be a helpful to support the design of optimized topologies. However, only 3-dimensional models could justify the decrease of mechanical properties on the porosity rate. Osteoconductive nanocomposite material with controlled growth delivery using SLS technique to form complex scaffolds will provide a potential route towards bone tissue regeneration. Controlled 
delivery of the growth factor in 3-dimensional $\mathrm{Ca}-\mathrm{P} / \mathrm{PHBV}$ [calcium phosphate /poly(hydroxybutyrate-co-hydroxyvalerate)] nanocomposite scaffolds having controlled and totally interconnected porous structure were successfully fabricated using selective laser sintering (SLS) [79]. Based on various models, nanocomposite scaffolds or porous structure consisting of $\mathrm{Ca}-\mathrm{P}$ nanoparticles and PHBV matrix were selectively sintered. A human proximal femoral condyle model was also constructed using SLS employing nanocomposite ( $\mathrm{Ca}-\mathrm{P} / \mathrm{PHBV})$. The incorporation of $\mathrm{Ca}-\mathrm{P}$ nanoparticles in scaffolds significantly improved cell proliferation and alkaline phosphatase (ALP) activity [79].

SLS and Silica Nanoparticles. H. Chung et al. recently investigated the unusual mechanical characteristics of PA-11 filled with different volume fractions of silica nanoparticles by selective laser sintering (SLS) from numerical simulation following the experimental results. The compressive modulus was predicted by two different numerical models and compared with the experimentally measured one. The compressive modulus calculated from the two-phase model continuously increases with the increase in volume fraction of nanoparticles and is consistent with the experimental results at $4 \%$ and $6 \%$ volume fraction of nanoparticles [80]. The simulation results by the two-phase model presents an increased modulus at $2 \%$ volume fraction of silica nanoparticles while the compressive modulus from the experiment demonstrates the decreased modulus at $2 \%$ volume fraction of silica nanoparticles. The effective interface model was introduced to match the unusual mechanical characteristics of PA-11 filled with $2 \%$ volume fraction of silica nanoparticles. The nano silica facilitates the powder flow and act as a flow agent due to its hydrophobic nature. It is selected for the study of hetero-phasic propylene-ethylene copolymer [81]. due to its nonpolar nature, which provides good compatibility with the nonpolar PP.

SLS and Metallic Nanoparticles. Physical parameters (powder bed temperature and laser power) has a great effect on sintered nanocomposites, for example curling or caking occurs in cases where the powder bed temperature is extremely low, consequently this results in a source of high thermal gradient between sintered and un-sintered powder or too high to melt the powder leading towards agglomeration process [82]. J. Bai et al reported an optimum temperature of $171^{\circ} \mathrm{C}-172^{\circ} \mathrm{C}$ at which the process will be free from curling and caking which limits the SLS process [12]. Moreover, the energy transfer from the laser beam to the substrate depends upon the absorptivity and thermal conductivity of the powder feedstock and the substrate [1]. Three-dimensional porous catalytic membranes (e.g., filters elements) using polycarbonate (PC) with copper and nickel nanoparticles were prepared by the SLS method for fuel cells and hydrogen storage applications [83]. Nickel and copper nanoparticles with sizes $15-200 \mathrm{~nm}$ and $70-120 \mathrm{~nm}$ were used respectively. The laser-assisted technique was used to prepare porous and stable polycarbonate structures containing encapsulated copper nanoparticles uniformly distributed over the sintered polymer. The incorporation of nanoparticles into the polymer matrix and the high speed laser heating-cooling cycles were reported to decelerate the nano particle coagulation during the SLS process [83]. Specimens of $\mathrm{PA}-12 / \mathrm{TiO}_{2}$ and $\mathrm{PA}-12 /$ functionalized graphite nanoplatelets nanocomposite were fabricated using SLS. Comparison of mechanical properties indicated that the functionalization of the nanofiller reinforces interfacial bonding forces. For this reason, a small amount of nanofiller, which does not influence the thermal and rheological behavior, can improve the materials mechanical properties [84]. The post sintering is also an important factor to improve quality of parts. A. Warnakula etc. evaluated processing parameters for SLS employing nanocomposites containing $\mathrm{Al}_{2} \mathrm{O}_{3}$ nanoparticles and polyamide matrix. The post sintering characterization showed evidence of sufficient inter-particle sintering and intra-layer coalescence. While the inter-particle coalescence gradually improved, the porosity levels slightly decreased with increasing laser power. The nano-filler particles tend to agglomerate around the beads along the solid tracks, possibly due to Van der Walls forces [85]. Moreover, material consolidation was improved when $\mathrm{Al}_{2} \mathrm{O}_{3}$ content was increased from $3 \mathrm{wt} \%$ to $10 \mathrm{wt} \%$, and the best consolidation was achieved at relatively higher laser powers $[72,85]$. Selective laser sintering (SLS) was used to prepare porous gradient polymer nanocomposites consisting of a polyetheretherketone (PEEK) matrix doped with alternating layers of $\mathrm{Ni}$ and $\mathrm{Cu}$ nanoparticles. It was reported that an insufficient 
agitation of mix led to a conglomeration of initial nanoparticles [86]. It was shown, that with the increase of layers number a figure of merit for multilayer system grows. The FG 3D parts with alternating ferromagnetic Ni-PEEK and non-magnetic Cu-PEEK layers exhibited hysteresis phenomena, which may be useful for use in micro/nano-electro-mechanical systems (MEMSNEMS) applications [86].

\section{Fused Deposition Modeling (FDM)}

Stratasys Inc. Company is the pioneer in the development of additive prototype system based on fused deposition modeling (FDM) utilizing an extrusion process to build 3D models [87]. FDM utilizes a solid material in the form a filament as a base or primary medium and extrude it using an elevated temperature and build the structure according to desired geometry in a layer by layer fashion, as shown in Fig. 17.

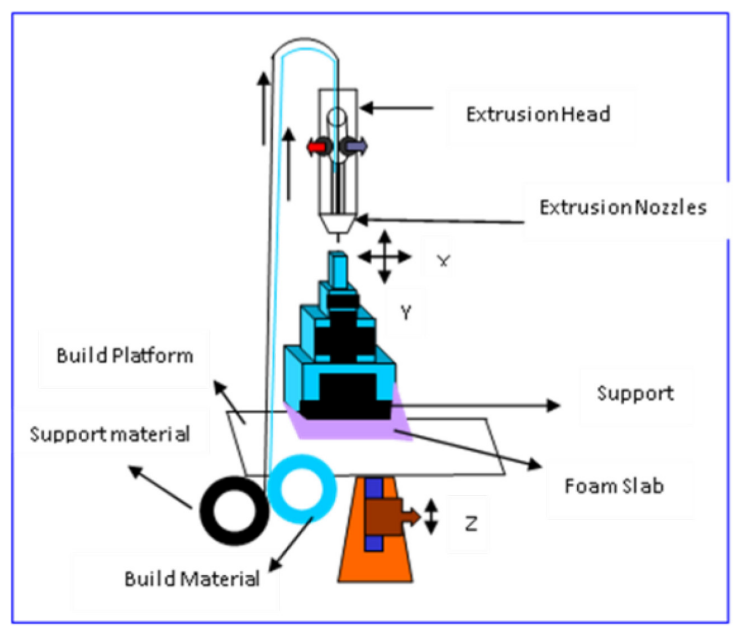

Figure 17. Model system for Fused Deposition Modeling (FDM).

FDM system is composed of CAD software which operates the work station that processes the files generating a layer-by-layer model deposition to build up the overall model. The slice thickness of each layer is variable ranging from $(0.178-0.356) \mathrm{mm}$ and can be adjusted according to the requirements [28]. The working principle of the FDM is multidisciplinary in its nature; a filament of material is fed into an extrusion head where it is melted, then layer manufacturing creates the horizontal layers and finally surface chemistry helps to understand the contacts between two successive layers. The build material most frequently used in the FDM process is currently polymers. The FDM technology to prepare nanocomposites is an emerging field. Its use was quite limited in the early phase but recently it use increases 10 fold due to cost and effectiveness. But the choice of material is still an issue which can be overcome through the use of nanocomposite materials. Different types of feedstock materials are available for FDM including thermoplastic polyester based elastomers; Polycarbonate (PC), polyphenylsulfone (PPS), poly(acrylonitrilebutadiene-styrene) (ABS) [88] and (PC/ABS) blends [89] The filler orientation in the molten thermoplastic strands achieves high thermal conductivity that is useful for applications in the field of electronics. The literature indicates that there might be compatibility issues involved in the preparation of nanocomposite filament in terms of machine parameters which can affect printed part quality. Significant progress was made in the recent years using nanocomposite into FDM. Overall, the FDM technique is getting attention using nanocomposites as raw material to improve structure of parts and scaffolds in effect of unique properties of nanoparticles.

FDM and Nano Clay. Silicates (Cloisite 30B) reinforced PLA nanocomposite filaments were successfully produced and printed using the FDM process. DSC investigations revealed the presence of two crystalline forms and a higher degree of crystallinity for the printed samples. The printed nanocomposites showed a higher elastic modulus (15\%) compared to printed samples of neat PLA. Moreover, printed nanocomposites offer better shape stability and edges formation [90]. ABS nanocomposites with organically modified montmorillonite (OMMT) were prepared by melt 
intercalation. The nanocomposite filaments were produced by a single screw extruder and printed by a commercial FDM printer. Results showed that the addition of $5 \mathrm{wt} \%$ OMMT improved the tensile strength $43 \%$ for 3D printed while $28.9 \%$ for injection moulded nanocomposites [91]. Significant improvements in mechanical properties, reduced porosity and better neck formation were observed for the polymer layered silicate nanocomposite [92]. Montmorillonite (MMT) belongs to smectite-type clay; the structure consists of an octahedral alumina sheet sandwiched between two tetrahedral silicate sheets, which form a layer. Recycled ABS in granular form was used for a base matrix.

FDM and Carbonaceous Nanoparticles. MWCNTs were dispersed in an ABS matrix through a master batch at different concentrations (from 1 to $8 \mathrm{wt} \%$ ), and the resulting materials were extruded in filaments suitable for the fused deposition modelling process. 3D printed samples were obtained under three different orientations. Overall, the mechanical, electrical and thermal properties of the bulk samples were increased by MWCNTs addition [93]. The 3D printing process led to a partial loss in the electrical conductivity, especially in horizontal and vertical configurations. Thermal properties of neat ABS were significantly influenced by the addition of CNT. It was reported that the print orientation and production process affect thermal diffusivity and conductivity which influence the properties of printed parts. Suitable nanocomposite (PA12/GNPs) filaments were fabricated and smoothly printed via a commercial FDM printer. The thermal conductivity and elastic modulus of printed parts along to the print direction exhibited $51.4 \%$ and $7 \%$ higher than that of compression moulded parts [94]. This enhancement was attributed to GNPs preferential alignment along to the print direction. The extrusion induced orientation of GNPs in PA12 matrix as determined through fracture surface SEM images of 3D printed parts [94]. Graphene nanoplatelets were successfully melting compounded in an ABS matrix by using a completely solvent-free process, and then extruded in filaments suitable for fused deposition modeling [95]. Due to the processing constraints, the filler content was optimized at $4 \mathrm{wt} \%$. The thermo-mechanical properties of neat ABS and its nanocomposites have been compared on samples obtained through various processing routes such as compression moulding, extrusion and fuseddeposition modelling. In all cases, the presence of graphene nanoplatelets improved the tensile modulus of ABS. This positive effect was also verified along several different orientations in FDM samples. Concurrently, the presence of $\mathrm{xGnP}$ causes a slight reduction of ultimate tensile stress and strain at break for horizontal and vertical 3D built specimens and a more severe effect along perpendicular direction [95]. Moreover, $\mathrm{xGnP}$ was also proven to reduce the coefficient of thermal dilation of 3D printed parts and to improve their stability under long lasting loads. In fact, the creep compliance significantly reduced by addition of the nanofiller. Graphene nanoplatelets resulted significant reinforcement effect in the FDM fabricated specimens along horizontal and vertical orientation and were observed to be less effective for perpendicularly printed specimens [95]. A series of the composites with various graphene loadings $(0.4,0.8,1.6,2.3,3.8,5.6$ and $7.4 \mathrm{wt} \%)$ were prepared for 3D printable computer-designed models. The composite's linear thermal coefficient is below $75\left[\mathrm{ppm} \cdot{ }^{\circ} \mathrm{C}^{-1}\right]$ from room temperature to its glass transition temperature $(\mathrm{Tg})$, which is crucial to build minute thermal stress during the printing process [96]. Discontinuous extrusion was observed for the $7.4 \mathrm{wt} \%$ sample in 3D printing process, indicating the material's inhomogeneity. It was observed that at a high graphene loading level $(7.4 \mathrm{wt} \%)$, aggregated graphene sheets could clog the printer's nozzle, resulting in the 3D printing failure [96]. The effects of the extrusion ratios of G-PLA and PLA, applied voltage and heat distribution on the printed items were investigated [97]. The mixed polymer is programmed and deposited on an assigned location and macroscopic physical properties of materials exhibit an anisotropic or gradient change. The mix ratio of the two extruded materials affected the resistance of the printed object and was controlled by the printer. The higher content of the conductive G-PLA in the printed objects led to a lower resistance, which caused a smaller heat effect when an electric field was applied on these objects [97]. A study reported, for the first time, FDM derived 3D-printed objects with chemiresistive properties in response to volatile organic compounds [98]. Printed sensing strips, with MWCNT loadings up to $15 \%$ mass, function as reversible vapour sensors with the strongest 
responses arising with organic compounds capable of readily intercalating and subsequently swelling the PVDF matrix (acetone and ethyl acetate) [98]. Furthermore, the sensors can be easily printed in different geometries, expanding their utility to wearable form factors. The schematic for the built sensor is shown in Fig. 18. Addition of carbon fibre (different content and length) into ABS plastic improved the mechanical properties of FDM-fabricated parts. The tensile strength and Young's modulus of printed specimens increased $22.5 \%$ and $30.5 \%$ for with $5 \mathrm{wt} \%$ and $7.5 \mathrm{wt} \%$ carbon fibre, respectively. CFRP composite specimen with $150 \mu \mathrm{m}$ carbon fibre had larger tensile strength and Young's modulus than that with $100 \mu \mathrm{m}$ carbon fibre. Compared with CFRP composite specimen with $100 \mu \mathrm{m}$ carbon fibre, specimen with $150 \mu \mathrm{m}$ carbon fibre had smaller toughness and ductility [99].

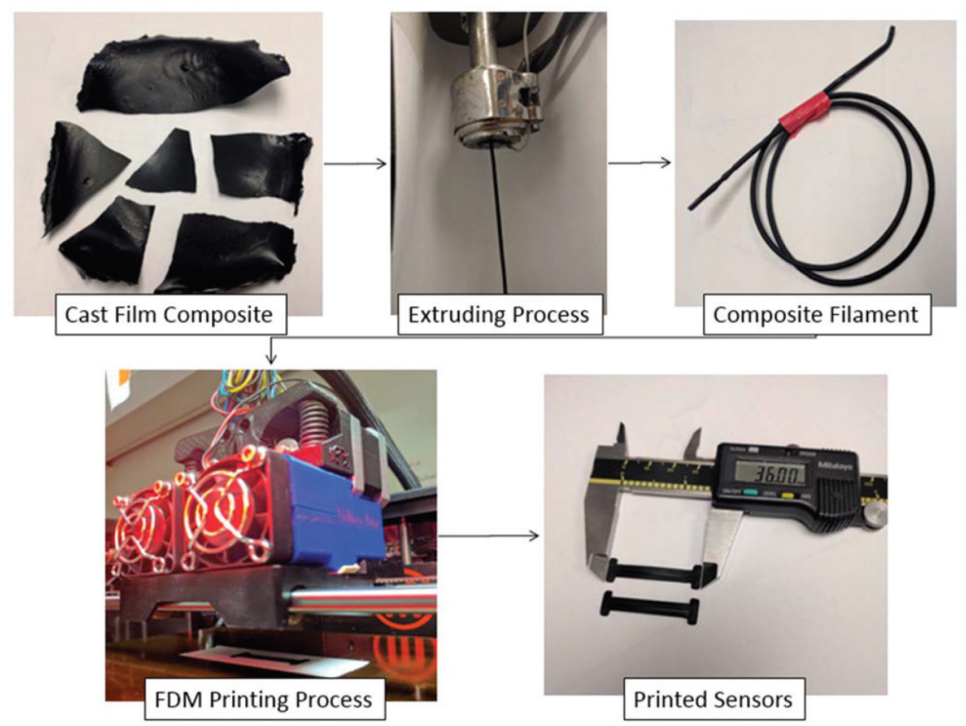

Figure 18. FDM 3D printing process used to produce vapor sensor strips. Courtesy of [98].

There was no significant difference in yield strength value between these two kinds of specimens. Porosity became the severest in the specimens with $10 \mathrm{wt} \%$ carbon fiber content. The porosity trend was consistent with the fracture interface observations results [99]. Graphene (Gr) has attracted impressive enthusiasm in the recent past due to its intrinsic mechanical, thermal, and electrical properties. FDM printed PLA/graphene nanocomposites containing $10 \mathrm{wt} \%$ graphene in PLA matrix were characterized for their mechanical, electrical and electromagnetic induction shielding properties of the nanocomposite [100]. The incorporation of multifunctional graphene substantially improved the electrical conductivity and dielectric constant values at low dielectric loss by simple 3D printed samples [100]. The enhancement in the electrical conductivity and the dielectric constant related to preferential alignment along deposited direction of the filaments and the polar characteristics of the graphene nano platelets to increases the number of charge carriers in the PLA matrix, respectively [100]. The feedstock filament has been prepared by two different methods (mechanical and chemical mixing) [100]. For mechanical mixing, a twin screw extrusion (TSE) process has been used, and for chemical mixing, the composite of Gr in an ABS matrix has been set by chemical dissolution, followed by mechanical blending through TSE. It was reported that the proportion of $\mathrm{Gr}$ in the ABS matrix is the significant parameter which influences the electrical conductivity, followed by the in-fill density and the process used for blending [101]. Whereas for thermal conductivity, the process used for blending (chemical and mechanical mixing), followed by in-fill density and proportion of Gr in the ABS matrix are significant parameters. The printability, electrical conductivity and mechanical stability of the polymer nanocomposites (PBT/CNT) before and after 3D (FDM) printing were evaluated [102]. The results show that 3Dprinted PBT/CNT objects have better conductive and mechanical properties and a better performance than 3D printed PBT/graphene structures [102]. The analysis showed that PBT/CNT $3 \mathrm{D}$ printed structures have better functional properties (elastic behavior and conductive properties) as well as esthetics than the PBT/Gr 3D printed structures [102]. 
FDM and Ceramic Nanoparticles. Y. D. Hazan et al. demonstrated the production of predetermined, complex $3 \mathrm{~d}$ ceramic/polymer nanocomposite fiber networks by robotic deposition of high loaded, solvent free UV curable ceramic colloidal inks using $\mathrm{Al}_{2} \mathrm{O}_{3}$ and hydroxyapatite (HA) particles for structural and biomedical applications. The $2 \mathrm{~d}$ and $3 \mathrm{~d}$ nanocomposites transform to macroscopic ceramics via thermal de-binding and sintering without delamination or distortion of the structure. Such versatile shaping platform is very promising for hydroxyapatite scaffolds [103]. J. Kim et al. prepared nanocomposites composed of poly (D, L-lactide: glycolide) (DL-PLGA) and $\beta$-tricalcium phosphate $(\beta$-TCP) for bone tissue engineering scaffolds applications via fused deposition modeling (FDM). The simple and complex scaffolds were produced with and without hydroxyapatite (HA) coating. Data suggest that all configurations of the scaffolds integrated with the host bone were biocompatible and thus may offer an exciting new scaffold platform for delivery of biological bone regeneration. The additive-prototyped nanocomposite scaffolds implanted into rabbit femoral defects were biocompatible, osteoconductive, supportive of bone deposition and biodegraded over 12 weeks. The HA coating produced no significant differences in scaffold degradation and bone regeneration in a rabbit femoral defect model [104].

FDM and Metallic Nanoparticles. M. Nikzad et al. investigated thermal and mechanical properties of parts processed through FDM employing metal powders, including iron particle with size $45 \mu \mathrm{m}$ and two types of copper particles with sizes $10 \mu \mathrm{m}$ and $45 \mu \mathrm{m}$, with ABS as polymer matrix. Test samples of Iron/ABS and Copper/ABS composites with metal content up to $40 \%$ by volume have been made by controlled centrifugal mixing followed by a single-screw extruder and compression moulding. Sample prototypes from the composite materials have been successfully made but in the initial stages factors like filament size variation, over filling, clogging of the nozzle and delamination of a few layers due to presence of plasticizer were reported that limit to attain optimum deposition [105]. These drawbacks were resolved by controlling suitable parameters for FDM like slice thickness, road width, fill patterns and nozzle diameter. Initially, a higher (double) built time for composite part was reported as compare to only ABS but optimizing the process parameters result in the build time down to almost the same as taken to build an equivalent part in ABS material using FDM technique. While FDM printing produce objects with mechanical properties similar to the original materials, metal-polymer blends cannot be used to print objects necessitating mechanical strength. From a recent study, significant reduction in tensile and bending were reported using composite materials containing relatively low $\%$ content of bronze and iron particles while composites at higher bronze (78\% metal) and magnetic iron (46\% metal) particles. The reduction in mechanical properties occurred du lack of adhesion and inhomogeneous distribution of metal particles within PLA [106].

\section{Success and Limitations}

The different functionalities of nanoparticles and developing trends in AM become source of motivation for this work. SL, SLS and FDM processes are discussed amongst different AM processes, in context to NPs usage, to manufacture parts with some functionality. A gradual growing trend is observed in the usage of nanocomposites into AM. The literature suggests that SL is relatively widely accepted nanocomposites process technique compares to SLS and FDM. In the recent years FDM have gained attention due to its cost and relatively easy to understand material fusing mechanism. A Pie chart (Fig. 19) is used to show NP \% usage in to AM based on the data collected for the present study. Nanoparticles from carbon family (CNTs, CNFs and graphene) are mostly used in AM compared to clay, ceramics, silica, metallic and semiconductor nanoparticles. 


\section{$\%$ uage of NP in the AM from the data collected for the present study}

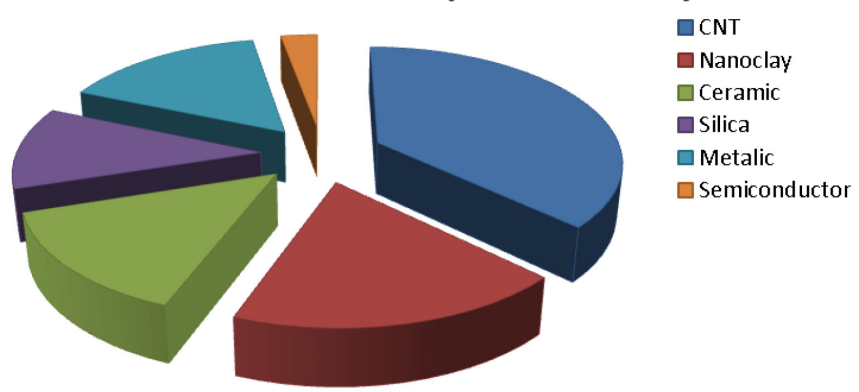

Figure 19. Comparative chart for AM processes employing nanocomposites based on the data used in this study. (b) \%usage of NPs used to print nanocomposites using AM.

Amongst a lot of efforts, very few functional parts were built including a micro gear, a scaffold, a flow sensor and vapour sensing strips. Most of the literature is devoted to explore possibilities to print mechanically strong parts and less consideration was given to print parts that can be used for some applications like electrical or mechanical devices. Nanocomposites can serve the purpose as the end goal of AM process to produce functional, cost effective and customize parts. The studies conducted in the past can be used as preliminary data to print parts that can benefit society. The choice of material for AM is limiting its wide implementation. The degree of the limitations of the available material for AM process, up to a certain extent, can be overcome through NP incorporation into host materials to improve different physical properties of materials. Moreover, poor surface quality, time consuming post-process and limited applications are the most common adverse effects due to which AM is still underway [13]. The strong link and the extremely small choice of material towards each process is a major constraint [107] in AM. Kevlar and polycarbonate based nanocomposites can be used in layer manufacturing due to their widely used applications in body armor and polycarbonate based automotive, respectively [108].

The errors and limitations associated with AM, employing nanocomposites, can be addressed by considering compatibility issues between matrix material and nano additives. For example, dispersion of nanoparticles into UV curable resin affects the curing process due to their ability to absorb the UV light, so a compatible UV-wavelength is of particular importance to consider for SL process. Nanocomposite, based on acrylic oligomer with magnetically responsive nanoparticles, cannot be obtained through micro stereolithography (MSL) due to baking steps involved before and after UV-exposure. A viscous resin was suggested to overcome problems occurred due to aggregation and sedimentation of large size magnetic particles to get a uniform dispersion [51].

Since, there is no quantitative measurement technique to understand the powder flow behavior, in particular to SLS process, due to which the processability of new material always remain a challenge. A quantitative powder flow characterization methodology is required to facilitate and understand SLS processing mechanism [109]. In SLS, a white light was reported [60] during sintering process which needs further research work to understand cause and emission of light. Sintering parameters (powder bed temperature and laser power) has a great effect on sintered nanocomposite for example curling or caking occurs in case of powder bed temperature is extremely low, consequently becomes a source of high thermal gradient between sintered and unsintered powder or too high to melt the powder leading towards agglomeration process [110]. Temperature optimization is required to print parts free from curling and caking [111]. Further study required to understand SLS technique and its parameters to get nanocomposites [60]. Formation of voids was reported in different studies which act to reduce density and strength of sintered nanocomposites. There is a gap to understand the cause and effect of these voids that can be extended to future work [61]. A through and comprehensive study is required to understand the formation, elimination and their effect as assistive or resistive to use in SLS process. 
Filament size variation, over filling of material and clogging of the nozzle were reported in FDM process that limits printed parts quality [112]. Clogging occurring during the FDM process can be overcome through the use of hit and trial methodology using nozzles with different bore sizes. Most of the FDM printer use pure polymer as input material to print parts. To use nanocomposites into FDM, an extruder is required to prepare nanocomposite filament, further to use in FDM to print parts. The dual printing process can affect the printed parts to acquire same features. One solution is to use a bio extruder that can print nanocomposites without preparing separate filaments. For example, a bio-extruder was used to fabricate 3D biodegradable scaffolds using (PCL/ cellulose nanofibers) and (PCL/ hydroxyapatite nanoparticles) nanocomposites with controlled architecture. Scaffolds were produced using a single lay-down pattern of $0 / 90 \circ$, with the same processing parameters as used in FDM. It was reported that the addition of cellulose nanofibers and hydroxyapatite nanoparticles did not impair the biocompatibility of the fabricated nanocomposites [113]. Such kinds of nanocomposite filaments are not available commercially. Bio-extruder is a straight forward additive layering process for scaffold fabrication using nanocomposites without involving special filament preparation. Another disadvantage of FDM is that the printable materials are limited to thermoplastic polymers with suitable melt viscosity. It is important to consider that molten viscosity of the printable polymer should be high enough to provide structural support and low enough to enable extrusion [114]. The complete removal of the support structure after printing process is also a difficult step. Notwithstanding these drawbacks, FDM printers also offer advantages, including low cost, high speed and simplicity. Moreover, FDM offers multi-material printing which is the key difference from other printing system that offers to print diverse materials simultaneously. Multiple extrusion nozzles are used to serve the purpose.

It is preferable to use NPs in future to AM processing for applications ranging from household appliances to military applications. The developments in natural polymers like chitosan, gelatin, and sodium alginate can help to overcome some toxicological problems with the synthetic polymers to print nontoxic nanocomposites. Resins from vegetables combined with chitosan NPs or gelatin NPs can lead to print biodegradable or ecologically sustainable AM parts.

\section{Conclusion}

AM having ability to fills the gap between available process techniques for nanocomposites. Their alliance could generate additional stream to push the nano revolution into a new phase. Overall, semi-encouraging results have been found in the application of nanocomposites into AM and the integration demands a comprehensive research work to fully address the complexities and inherent potential. The following conclusions are drawn from the study:

1. Not much work had done in this field and it requires more attention to understand the compatibility issues between nanoparticles and host materials. The literature survey reveals that few rapid manufacturing techniques were employed in which nanocomposites used as raw material. There is a need to employ other rapid manufacturing techniques to process nanocomposites as a raw material for rapid part fabrication that may prove useful like laminated object manufacturing, plasma sintering, etc.

2. Enhanced mechanical and electrical properties were observed in different attempts indicating the feasibility and use of nanocomposites in rapid manufacturing techniques. Mechanical properties were investigated more as compared to other physical properties, for example a few people investigated the enhancement in electrical conductivity of nanocomposites for rapid manufacturing applications.

3. Dispersions containing nanoparticles with high UV-vis absorption are not suitable to employ them in UV-curable resin to construct prototype. UV-vis absorption of nanoparticles must be comparable to intensity of UV radiations to get a good spinning, curing and hence solidification of nanocomposite fiber.

4. Suitable photopolymers are critical for the SL process. Important characteristics, such as viscosity, sensitivity, and wavelength response need to be considered for the SL application. 
5. Possibly, a portion of UV energy absorbed by nanoparticles can lead towards insufficient curing of UV resin. Therefore, a prior knowledge or study can help to avoid incomplete cure in the printed parts.

6. Streolithography system optimization is required to avoid post processing. Right choice and optimum amount of NPs can help to get fully cured parts.

7. Efficient methodologies are required to reduce viscosity rise caused by NPs insertion into the UV curable resins.

8. The sintering temperature has significant effects on aggregation and caking of nanoparticles during SLS process.

9. Nanocomposite powder with spherical shape is preferred over square-edged particles to construct 3D objects.

10. Degassing the materials polymer and nanoparticles can help to overcome porosity and can enhance mechanical properties for the printed parts.

11. An efficient powder production method/system can produce powders with uniform morphology and facilitates sintering process to improve mechanical properties of the printed parts.

12. Processing conditions, including laser power, scan speed, bed temperatures and chamber temperatures are equally important during sintering process. The quality of manufactured part depends on optimum conditions. It is advisable to carefully select optimum conditions to print parts which changes from material to material.

13. Due to stair step effect a rough surface finish is produced which make components less detailed due to a high processing temperature and high shrinkage and demands a comprehensive research work in future.

14. It is evident that nature of host material in most of the studies was PA whereas a different trend is observed in case of nano additives ranging from CNTs, carbon black, clay nanoparticles in the SLS process. The reason to use carbon nanofiller is their high aspect ratio leading towards high mechanical strength and conductivity while PA is available commercially as well as naturally, beside that indicates limitations of materials in case of SLS technique as compare to traditional manufacturing process.

15. FDM is limited by the availability of application specific functional materials. Thermoplastic polymers with nano additives can help to delimit the choice of specific functional materials.

16. Nozzle wear during the FDM printing process can also affect the print quality. It is advice able to monitor nozzle after some usage. Hardened steel nozzles can serve the purpose to overcome nozzle abrasion.

17. The homogeneous dispersion of nano additives into a polymer matrix is necessary to achieve desired functionality in the printed nanocomposites.

18. Exploiting nanostructured material characteristics and properties in AM may open new window for markets offering rapidly manufactured functional devices.

19. Several research questions still need to address for the success and implementation of the technological merger. There is a need of new materials that can fulfil requirements required for 3D printing including flow rate, crystallization and shrinking properties.

20. Theoretical models required to fully understand the behavior of nanoparticles during part fabrication and explaining the compatibility issues between nanoparticles and matrix material during layering process.

\section{Acknowledgement}

This work is supported by the Fundação para a Ciência e a Tecnologia (FCT) and Centro2020 through the Project references: UID/Multi/04044/2013; PAMI - ROTEIRO/0328/2013 (No 022158) and Additive Milling (co- promoção n.o 3414). 


\section{References}

[1] S. Seal, S.C. Kuiry, P. Georgieva, A. Agarwal, Manufacturing Nanocomposite Parts: Present Status and Future Challenges, MRS Bull. 29 (2004) 16-21.

[2] M. De, P.S. Ghosh,V.M. Rotello, Applications of Nanoparticles in Biology, Adv. Mat. 20 (2008) 4225-4241.

[3] A. Agrawal, J.P. Cronim, Metal coatings, conductive nanoparticles and. US8749869 B2 US, 2012.

[4] S.D. Mohan, M. Belbut, C.S. Kamma-Lorger, A. Mateus, G.R. Mitchell I. Khan, Multiscale Structure Evolution in Electrically Conductive Nanocomposites Studied by SAXS, Proc. Manuf. 12, 79-88 (2017).

[5] G. Matzeu, A. Pucci, S. Savi, M. Romanelli, F.Di Francesco, A temperature sensor based on a MWCNT/SEBS nanocomposite, Sen. Act. A: Physical, 178 (2012) 94-99.

[6] A. Ashori, S. Sheshmani, F. Farhani, Preparation and characterization, Carbo. Poly. (2013) 865871.

[7] G. Tegart, Nanotechnology: the technology for the twenty-first century, The Journal of Future Studies, Strat. Think. Pol. 6 (2004) 364-370.

[8] D. Lukkassen, A. Meidell, Advanced materials and structures and their fabrication processes. Narvik : Narvik University College, (2007).

[9] L. Li, M. Hong, M. Schmidt, M. Zhong, A. Malshe, B.H. veld, V.r Kovalenko, Laser nano Manufacturing-state of the art and challenges, CIRP Annals-Man. Tech. 60 (2011) 735-755.

[10] Y. Yongnian, L. Shengjie, Z. Renji, L. Feng, W. Rendong, L. Qingping, X. Zhuo, W. Xiaohong, Rapid prototyping and manufacturing technology: Principle, representative technics, applications, and development trends, Tsing. Sc. Tech. 14 (2009) 1-12.

[11] J. Kim, T.S. Creasy, Selective laser sintering characteristics of nylon 6/clay- reinforced nanocomposite, Poly. Test. 23 (2004) 629-636.

[12] J. Bai, R.D. Goodridge, R.J.M. Hague, M. Song, Carbon nanotube reinforced Polyamide 12 nanocomposites for laser sintering, SFF Symp. Proce. (2012).

[13] S.G. Kim, W.S. Chu, W.K. Jung, S.H. Ahn, Evaluation of mechanical and electrical properties of nanocomposite parts fabricated by nanocomposite deposition system (NCDS), Jour. Mat. Proc. Tech. 187-188 (2007) 331-334.

[14] H. Khalil, H.J. Gläsell, M.R. Buchmeiser, High-Mechanical Strength Flame-Retardant Nanocomposites Based on Novel Al(III)- and Zr(IV) Melamine Phosphates and Sulfates, Macr. Mat. Eng. (2012).

[15] J.A. Scholl, A.L. Koh, J.A. Dionne, Quantum Plasmon resonances of individual metallic nanoparticles, Nature, 483 (2012) 421-428.

[16] R. Hague, I. Campbell, P. Dickens, Implications on design of rapid manufacturing Proceedings of the Institution of Mechanical Engineers Part C; Jour. Mech. Eng. Sci. 217 (2003) 25-30.

[17] T. Gutowski, S. Jiang, D. Cooper, G. Corman, M. Hausman, J.A. Manson, T. Schudeleit, K.Wegener, M. Sabelle, J.R. Grez, D.P. Sekulic, Note on the Rate and Energy Efficiency Limits for Additive Manufacturing, Journal of Industrial Ecology (2017)

[18] M. Salmi, K.S. Paloheimo, J. Tuomi, J. Wolff, A. Mäkitie, Accuracy of medical models made by additive manufacturing (rapid manufacturing), Jour. Cranio. Max. Surg. (2013) 
[19] C.A. Brice, F.J. Herman, Rapid Manufacturing of Carbon Nanotube Composite Structures, Patent US B2 6,949,216 (2005).

[20] J.W. Choi, C.X. Liu, Improved dispersion of carbon nanotubes in polymers at high concentrations, Nanomaterials. 2 (2012) 329-347.

[21] C. Kuebel, G. Ilari, F. Rechberger, F.J. Heiligtag, M. Niederberger, D. Koziej, R. Ernia, M.D. Rossell, Impact of sonication pretreatment on carbon nanotubes: A transmission electron microscopy study, Carbon, vol. 61, pp. 404-411, 2013.

[22] M. Kontopoulou, H. Gui, A. Docoslis A.A. Vasileiou, Correlation between the length reduction of carbon nanotubes and the electrical percolation threshold of melt compounded polyolefin composites, ACS Appl. Mater. Inter. 7 (2015) 1624-1631.

[23] R. Kaushala, S.K. Tripathib, A.L. Sharmaa, I. Kaura, L.M. Bharadwaja R. Rastogia, Comparative study of carbon nanotube dispersion using surfactants, Jour. Col. and Inter. Sci. 328 (2008) 421-428.

[24] S.D. Mohan, F.J Davis, G.R Mitchel M. Nazhipkyzy, Carbon nanotubes in electrospun polyethylene oxide nanofibres: A potential route to conducting nanofibres, Jour. Phy.: Conf. Ser. 246 (2015).

[25] T.W. Chou, E.T. Thostenson, Aligned multi-walled carbon nanotube-reinforced composites: processing and mechanical characterization, J. Phys. D: Appl. Phys. 35 (2002) 77-80.

[26] A.R. Bhattacharyya, A. Janke. P. Pötschke, Melt mixing of polycarbonate with multiwalled carbon nanotubes: microscopic studies on the state of dispersion, Eur. Pol. Jour. 40 (2004) 137-148.

[27] K. Balasubramanian, M. Burghard, Chemically functionalized carbon nanotubes, Small, 1 (2005) $180-192$.

[28] C.K. Chua, K.F. Leong, C.S. Lim, Rapid Prototyping: Principles and Applications. singapore : 3rd edition, World Scientific Publishing company, (2010).

[29] P.F. Jacobs, Rapid Prototyping and Manufacturing, Fundamentals of Stereolithography, Society of Manufacturing Engineers. (1992) 11-18.

[30] M.S. Bajerlaina, H. Gojzewskib, E. Andrzejewska, Monomer/modified nanosilica systems: Photopolymerization kinetics and composite characterization, Polymer, 52 (2011) 1495-1503.

[31] S. Danu, D.D. Marsongko, UV-curing of titanium dioxide pigmented epoxy acrylate coating on ceramic tiles, Journal of the Ceramic Society of Japan 116 (2008) 896-903.

[32] T.H. Pang, StereoLithography Epoxy Resin Development:Accuracy and Dimensional Stability, Proc. NAUGM, Georgia, (1993).

[33] M. Gurr, Y. Thomann, M. Nedelcu, R. Kübler, L. Könczöl, R. Mülhaupt, Novel acrylic nanocomposites containing in-situ formed calcium phosphate/layered silicate hybrid nanoparticles for photochemical rapid prototyping, rapid tooling and rapid manufacturing processes, Polymer, 51 (2010) 5058-5070.

[34] S. Sharifi, S.B.G. Blanquer, T.G.V Kooten, D.W. Grijpma, Biodegradable nanocomposite hydrogel structures with enhanced mechanical properties prepared by photo-crosslinking solutions of poly(trimethylene carbonate)-poly(ethylene glycol)-poly(trimethylene carbonate) macromonomers and nanoclay particles, Acta Biom. 8 (2012) 4233-4243.

[35] C.E. Corcione, R. Striani, F. Montagna, D. Cannoletta, Organically modified montmorillonite polymer nanocomposites for stereolithography building process, Poly. Adv. Tech. 26 (2015) 92-98.

[36] L. Wu, Z. Weng, Y. Zhou, Xian, s.n., Preparation and Properties of SLA and FDM 3d printed polymer nanocomposites, 21st International Conf. Comp. Mat., (2017). 
[37] J.H. Sandoval, R.B. Wicker, 5, Functionalizing stereolithography resins:effects of dispersed multi-walled carbon nanotubes on physical properties, Rap. Pro.Jour. 12 (2006) 292-303.

[38] J.H. Sandoval, K.F. Soto, L.E. Murr, R.B. Wicker, J. Sci Mater, Nanotailoring photocrosslinkable epoxy resins with multi-walled carbon nanotubes for stereolithography layered manufacturing, 42 (2007) 156-165.

[39] P. Harris, Carbon nanotubes and related structures, UK : Cambridge University Press, (1999).

[40] D. Lin, S. Jin, F. Zhang, C. Wang, Y. Wang, C. Zhou, G.J. Cheng, 3D stereolithography printing of graphene oxide reinforced complex architectures, Nanotechnology, 26 (2015).

[41] G.W. Hadipoespito, Y. Yang, H. Choi, G. Ning, X. Li, Digital Micromirror Device Based Microstereolithography for Micro Structures of Transparent Photopolymer and Nanocomposites, Proc. SFF Texas, (2003) 13-24.

[42] A. Ronca, L. Ambrosio, D.W. Grijpma, Preparation of designed poly(D,L-lactide)/nanohydroxyapatite composite structures by stereolithography, Acta Biom., (2012).

[43] W. Zhu, B. Holmes, R.I. Glazer, L.G. Zhang, 3D printed nanocomposite matrix for the study of breast cancer bone metastasis, Nanomedicine: Nanotechnology, Biology, and Medicine, 12 (2016) 69-79.

[44] S. Kirihara, Structural Joining of Ceramics Nanoparticles: Development of Photonic Crystals for Terahertz Wave Control by Using Micro Stereolithography, Powd. Part. Jour. 27 (2009) 107118.

[45] Y. Yang, Z. Chen, X. Song, B. Zhu, T. Hsiai, P.I. Wu, R. Xiong, J. Shi , Y. Chen, Q. Zhou, K.K. Shung, Three dimensional printing of high dielectric capacitor using projection based stereolithography method, Nano Energy, 22 (2016) 414-421.

[46] Matthias Gurr, Daniel Hofmann, Michael Ehm, Yi Thomann, Rainer Kubler, Rolf Mulhaupt, Acrylic Nanocomposite Resins for Use in Stereolithography and Structural Light Modulation Based Rapid Prototyping and Rapid Manufacturing Technologies, Advance Functional Materials, 18 (2008) 2390-2397.

[47] F. Kotz, K. Arnold, W. Bauer, D. Schild, N. Keller, K. Sachsenheimer, T.M. Nargang, C. Richter, D. Helmer , B.E. Rapp, Three-dimensional printing of transparent fused silica glass, Nature, 544 (2017) 337-342.

[48] S.R. Raghavan, H. Walls, S.A. Khan, Rheology of silica dispersions in organic liquids: new evidence for solvation forces dictated by hydrogen bonding, Langmuir, 16 (2000) 7920-7930.

[49] T.A. Pham, D.P. Kim, T.W. Lim, S.H. Park, D.Y. Yang, K.S. Lee, Three-Dimensional SiCN Ceramic Microstructures via Nano-Stereolithography of Inorganic Polymer Photoresists, Advanced Functional Materials, 16 (2006) 1235-1241.

[50] S. Maruo, T. Saeki, Y. Kanazawa, Y. Ichiyanagi, Magnetically driven micropump produced by microstereolithography with ferrite nanoparticle composite photopolymer, MicroNanoMechatronics and Human Science,International Symposium, (2008)291-294 .

[51] S.J. Leigha, C.P. Purssella, J. Bowenb, D.A. Hutchinsa, J.A. Covingtona, D.R. Billsona, A miniature flow sensor fabricated by micro stereolithography employing a magnetite/acrylic nanocomposite resin, Sen. Act. A: Physical, 168 (2011) 66-71.

[52] Y.D. Hazan, V. Märkl, J. Heinecke, C. Aneziris, T. Graule, Functional ceramic and nanocomposite fibers, cellular articles and microspheres via radiation curable colloidal dispersion, Jour. Eur. Cer. Soc. 31 (2011) 2601-2611. 
[53] A.J. Lopesa, I.H. Leeb, E. MacDonald, R. Quintana, R. Wickera, Laser curing of silver-based conductive inks for in situ 3D structuralelectronics fabrication in stereolithography, Jour. Mat. Proc. Tech. 214 (2014) 1935-1945.

[54] K.K. Jang, P. Prabhakaran, D. Chandran, J.J. Park, K.S. Lee, Solution processable and photopatternable blue, green and red quantum dots suitable for full color displays devices, Opt. Mat. Exp. 2 (2012) 519-525.

[55] F. Deubel, M. Steenackers, J.A. Garrido, M. Stutzmann, R. Jordan, semiconductor/polymer nanocomposites of acrylates and nanocrystalline silicon by laser-induced thermal polymerization, Mater. Eng. (2013).

[56] S. Kumar, J.P. Kruth, Composites by rapid prototyping technology, Mat. Des. 31 (2010) 850856.

[57] H. Chung, S. Das, Functionally graded Nylon-11/silica nanocomposites produced by selective laser sintering, Materials Science and Engineering A, 487 (2008) 251-257.

[58] J.P. Kruth, G. Levy , F. Klocke, T. Childs, Consolidation phenomena in laser and powder-bed based layer manufacturing, Ann CIRP, 56(2) (2007) 730-59.

[59] J. Kim, T.S. Creasy, The SLS Characteristics of $1.8 \mathrm{wt} \%$ Clay Nanoparticle/Nylon 6 Composite, SFFF Proc. (2002) 224-230.

[60] J.H. Koo, L. Pilato, G. Wissler, J. Cheng, W. Ho, K. Nguyen, S. Lao, A. Cummings, M. Ervin., Innovative Selective laser Sintering Rapid manufacturing using Nanotechnology, Proc. SFF Symposium, Texas (2005).

[61] M.S. Wahab, K.W. Dalgarno, R.F. Cochrane, S. Hassan, Development of polymer nanocomposites for rapid manufacturing application, Proc. W. Cong. Eng.1 London (2009).

[62] A. Greco, A. Maffezzoli, E. Calo, C. Massaro, R. Terzi, An investigation into sintering of PA6 nanocomposite powders for rotational molding, J. Therm Anal Calorim, 109 (2012) 1493-1502.

[63] J. Bai, R.D. Goodridge, R.J.M. Hague, M. Okamoto, Processing and characterization of a polylactic acid/nanoclay composite for laser sintering, Poly. Comp. (2012).

[64] J. Bai, R.D. Goodridge, R.J.M. Hague, M. Okamoto, Processing and characterization of a polylactic acid/nanoclay composite for laser sintering, Poly. Comp. (2015)

[65] G.V. Salmoria, R, A. Paggi, A. Lago, V.E. Beal, Microstructural and mechanical characterization of PA12/MWCNTs nanocomposite manufactured by selective laser sintering, Polymer Testing 30 (2011) 611-615.

[66] J. Bai, R.D. Goodridge, S. Yuan, K. Zhou, C. K. Chua, J Wei, Thermal Influence of CNT on the Polyamide 12 Nanocomposite for Selective Laser Sintering, Molecules, 20 (2015) 19041-19050.

[67] S. Yuan, J. Bai , C. K. Chua , J. Wei , K. Zhou, Material Evaluation and Process Optimization of CNT-Coated Polymer Powders for Selective Laser Sintering, Polymers, 8 (2016) .

[68] J. Bai, S. Yuan, F. Shen, B. Zhang, C. K. Chua, K.Zhou, J. Wei, Toughening of polyamide 11 with carbon nanotubes for additive manufacturing, Vir. and Phy. Prot. 12 (2017) 235-240.

[69] S.C. Lao, M.F. Kan, C.K. Lam, D.Z. Chen, J.H. Koo, T. Moon, M. Londa, E.T. Takatsuka, K. Uramoto, G. Wissler, L. Pilato, Z.P. Luo, Polyamide11-carbon nano tubes Nanocomposites: processing, morphological, and property characterization, SAMPE, (2010).

[70] S. Lao, J.H. Koo, A. Morgan, H. Jor, K. Nguyen, G. Wissler, L. Pilato, Z.P. Luo, Fire retardant intumescent polyamide 11 nanocomposites, SAMPE, California (2007). 
[71] D.Z. Chen, S Lao, J.H. Koo, M. Londa, Z. Alabullatif., Powder processing and property characterization of Polyamide 11- Graphene Nano composites for selective laser sintering,. SAMPE, (2011).

[72] B. Chen, S. Berretta, K. Evans, K. Smith, O. Ghita, A primary study into graphene/polyether ether ketone (PEEK) nanocomposite for laser sintering, App. Surf. Sci., 428 (2018) 1018-1028.

[73] R.D. Goodridge, M.L. Shofner, R.J.M. Hague, M. McClelland, M.R. Schlea , R.B. Johnson ,C.J. Tuck, Processing of a Polyamide-12/carbon nanofibre composite by laser sintering, Polymer Testing, 30 (2011) 94-100.

[74] W. Zhu, C. Yan, Y. Shi, S. Wen, J. Liu, Q. Wei, Y. Shi, A novel method based on selective laser sintering for preparing high-performance carbon fibres/ polyamide12/epoxy ternary composites, Scientific Reports, 6(33780) (2016).

[75] E. Taghipour, M.C. Leu, N. Guo, Comparison of Compression Molding and Selective Laser Sintering Processes in the Development of Composite Bipolar Plates for Proton Exchange Membrane Fuel Cells, 21th International SFF Symposium, Austin, (2012).

[76] Siddharth Ram Athreya, Kyriaki Kalaitzidou, Suman Das, Processing and characterization of a carbon black-filled electrically conductive Nylon-12 nanocomposite produced by selective laser sintering, Mat. Sci. and Eng. A 527 (2010) 2637-2642.

[77] S. Eshraghi, S. Das, Micromechanical finite-element modeling and experimental characterization of the compressive mechanical properties of polycaprolactone-hydroxyapatite composite scaffolds prepared by selective laser sintering for bone tissue engineering, Acta Biomaterialia, 8 (2012) 3138-3143.

[78] A. Cerardi, M. Caneri, R. Meneghello, G. Concheri, M. Ricotta, Mechanical characterization of polyamide cellular structures fabricated using selective laser sintering technologies, Materials \& Design, 46 (2013) 910-915.

[79] B. Duan, M. Wang, Customized Ca-P/PHBV nanocomposite scaffolds for bone tissue engineering: design, fabrication, surface modification and sustained release of growth factor, J. R. Soc. Interface, 7 (2010) S615-S629.

[80] H. Chung, S. Kong, D. Kim, Study on the Compressive Modulus of Nylon-11/Silica Nanocomposites, Jour. Nanomat. 2012 (2012).

[81] M.M. Lexow, D. Drummer, New Materials for SLS: The Use of Antistatic and Flow Agents, Jour. Powd. Tech. 2016 (2016).

[82] E.D. Jr. Dickens, B.L. Lee, G.A. Taylor, A.J. Magistro, H. Ng, K. McAlea, P.F. Forderhase, Sinterable semi-crystalline powder and near-fully dense article formed therewith. 5,527,877, (1994).

[83] I.V. Shishkovsky, A.Vl. Bulanova, Y.G. Morozov, Porous Polycarbonate Membranes with Ni and $\mathrm{Cu}$ Nano Catalytic Additives Fabricated by Selective Laser Sintering, Jour. Mat. Sci. and Eng. B 2 (2012) 634-639.

[84] H.C. Kim, H.T. Hahn, Y.S. Yang, Synthesis of PA12/functionalized GNP nanocomposite powders for the selective laser sintering process, Jou. Comp. Mat., (2012).

[85] A. Warnakula, S. Singamneni, Selective Laser Sintering of Nano A12O3 Infused Polyamide, Materials, 10 (2017).

[86] I.V. Shishkovsky, V.I. Scherbakov, I.N. Saraeva, A.A. Ionin, Thermoelectric properties of gradient polymer composites with nano-inclusions fabricated by laser assisted sintering, Laser Phy. Let. 14 (2017). 
[87] J.M. Usher, U. Roy, H.R. Parsaei, Integrated Product and Process development; methods, tools and technologies, 1st edi., John Wiley \& sons, New Jersey, (1998).

[88] M. Koc, T. Ozel, Micro-Manufcturing: Design and Manufacturing of Micro-Products, $1^{\text {st }}$ edi., John Wiley \& sons, New Jersey, (2010).

[89] B. Wendel, D. Rietzel, F. Kuhnlein, R. Feulner, G. Hulder, E. Schmachtenberg, Additive Processing of Polymers, Macromol. Mater. Eng., 293 (2008) 799-809.

[90] B. Coppola, N. Cappetti, L. Di Maio, P. Scarfato, L. Incarnato, Italy : IEEE, Layered Silicate Reinforced Polylactic Acid Filaments for 3D Printing of Polymer Nanocomposites, RTSI (2017).

[91] Z. Weng, J. Wang , T. Senthil, L. Wu, Mechanical and thermal properties of $\mathrm{ABS} /$ montmorillonite nanocomposites for fused deposition modeling 3D printing, Materials and Design, 102 (2016) 276-283.

[92] V. Francis, P.K. Jain, Experimental investigations on fused deposition modelling of polymerlayered silicate nanocomposite, Virtual and Physical Prototyping, 11 (2016) 109-121.

[93] A. Dorigato, V. Moretti, S. Dul, S.H. Unterberger, A. Pegoretti, Electrically conductive nanocomposites for fused deposition modelling, Synthetic Metals, 226 (2017) 7-14.

[94] D. Zhu, Y. Ren, G. Liao, S. Jiang, F. Liu, Thermal and mechanical properties of polyamide 12/graphene nanoplatelets nanocomposites and parts fabricated by fused deposition, Journal of Applied Polymer Science, (2017) 45332.

[95] S. Dul, L. Fambri, A. Pegoretti, Fused deposition modelling with ABS-graphene nanocomposites, Composites: Part A, 85 (2016) 181-191.

[96] X. Wei, D. Li, W. Jiang, Z. Gu, X. Wang, Z. Zhang, Z. Sun, 3D Printable Graphene Composite, Scientific Reports, 5:11181 (2015).

[97] Y. Zhuang, W. Song, G. Ning, X. Sun, Z. Sun, G. Xu, B. Zhang, Y. Chen, S. Tao, 3D-printing of materials with anisotropic heat distribution using conductive, Materials \& Design, 126 (2017) 135-140.

[98] Z.C. Kennedy, J.F. Christ, K.A. Evans, B.W. Arey, L.E. Sweet, M.G. Warner, R.L. Erikson, C. A. Barrett, 3D-printed poly(vinylidene fluoride)/carbon nanotube composites as a tuneable, lowcost chemical vapour sensing platform, Nanoscale, 9 (2017) 5458-5466.

[99] F. Ning, W. Cong, J. Qiu, J. Wei, S. Wang, Additive manufacturing of carbon fiber reinforced thermoplastic composites using fused deposition modeling, Composites Part B, 80 (2015) 369-378.

[100] K. Prashantha, F. Roger, Multifunctional properties of 3D printed poly(lactic acid)/graphene nanocomposites by fused deposition modeling, Jour. Mac. Sci. Part A, 54 (2017) 24-29.

[101] R. Singh, G.S. Sandhu, R. Penna , I. Farina, Investigations for Thermal and Electrical Conductivity of ABS-Graphene Blended Prototypes, Materials, (2017) 881-894.

[102] K. Gnanasekaran, T. Heijmans, S.V. Bennekom, H. Woldhuis, S. Wijnia, G. de With, H. Friedrich, 3D printing of CNT- and graphene-based conductive polymer nanocomposites by fused deposition modeling, App. Mat. Tod. 9 (2017) 21-28.

[103] Y.D. Hazan, M. Thänert, M. Trunec, J. Misak, Robotic deposition of 3d nanocomposite and ceramic fiber architectures via UV curable colloidal inks, J. Eur. Cer. Soc. 32 (2012) 1187-1198.

[104] J. Kim, S. McBride, B. Tellis, P.A. Urena, Y.H. Song, D.D. Dean, V.L. Sylvia, H. Elgendy, J. Ong, J.O. Hollinger, Rapid-prototyped PLGA/ß-TCP/hydroxyapatite nanocomposite scaffolds in a rabbit femoral defect model, Biofabrication, 4 (2012).

[105] M. Nikzad, S.H. Masood., I. Sbarski, Thermo-mechanical properties of a highly filled polymeric composites for Fused Deposition Modeling, Materials and Design, 32 (2011) 3448-3456. 
[106] S. Fafenrot, N. Grimmelsmann, M. Wortmann, A. Ehrmann, Three-Dimensional (3D) Printing of Polymer-Metal Hybrid Materials by Fused Deposition Modeling, Materials 10 (2017).

[107] J.P. Kruth, M.C. Leu, T. Nakagawa, Progress in Additive Manufacturing and Rapid Prototyping, CIRP Annals, 47 (1998) 525-540.

[108] A.K. Kaushik, Deformation Mechanisms in Polymer-Clay Nanocomposites, Ph.D. Thesis, The University of Michigan, Ann Arbor. (2010).

[109] S. Lao, K. Nguyen, D. Ho, T. Cummings, J.H. Koo, J. Cheng, SLS Processing of Nylon 11 Nanocomposites, 17th SFF Symposium, Texas, (2005).

[110] E.D. Dickens, B.L. Lee, G.A. Taylor, A.J. Magistro, H. Ng, K. Mcalea and P. F. Forderhase, Sinterable semi-crystalline powder and near-fully dense article formed therewith, US Patent 5527877 A (1994).

[111] R.D. Goodridge, R.J.M. Hague, M.S.J. Bai, Carbon nanotube reinforced polyamide12 nanocomposites for laser sintering, SFF Symposium Proc. 2012.

[112] W.Q. Song, S.H. Masood, Development of new metal/polymer materials for rapid tooling using fused deposition modelling, Mat. \& Design Jour. 25 (2004) 587-594.

[113] S. Biscaia, T. Viana, M. Franco, C. Malça, A. Mateus, C. Moura, F.C. Ferreira P. Morouço, Fabrication of poly( $\varepsilon$-caprolactone) scaffolds reinforced with cellulose nanofibers, with and without the addition of hydroxyapatite nanoparticles, BioMed Res. Inter. 2016 (2016).

[114] M. Jiang, Z. Zhou, J. Gou, D. Hui, X. Wang, 3D printing of polymer matrix composites: A review and prospective, Comp. and Eng. Part B.110 (2017) 442-458. 